\title{
Optimal Decision-Making under Uncertainty - Application to Power Transmission Investments
}

\author{
Gerardo Blanco ${ }^{1}$ and Fernando Olsina ${ }^{2}$ \\ ${ }^{1}$ Facultad Politécnica, Universidad Nacional de Asunción, \\ 2Institute of Electrical Energy, National University of San Juan, \\ ${ }^{1}$ Paraguay \\ ${ }^{2}$ Argentina
}

\section{Introduction}

Investment could be defined as the act of incurring immediate costs with the expectation of future returns. An investment project, as every asset has a value. Thus, for successfully investing in and managing these assets is crucial not only recognizing what the value is but also the sources of this value (Damodaran, 2002).

Most investment decisions share three important characteristics in different degrees. First, investments are partially or totally irreversible. Roughly speaking, the initial investment cost is at least partially sunk; i.e. it is impossible to recover all the expenditures if the decision-maker changes her mind. Second, there is uncertainty in the revenues from the investment, and therefore, risk associated with this. Third, all decision-making has some leeway about the timing of the investment. It is possible to defer the decision making to get more information about the future. These three features interact to determine the optimal decisions of investors on a given investment project (Dixit \& Pindick, 1994).

Transmission utilities are faced with investments, which hold these three characteristics significantly: irreversibility, uncertainty and the choice of timing. In this context, an efficient decision making process is, therefore, based on managing the uncertainties and understanding the relationships between risks and opportunities in order to achieve a welltimed investment execution.

Therefore, strategic flexibility for seizing opportunities and cutting losses contingent upon the market evolution is of huge value. Strategic flexibility is a risk management method that is gaining ongoing research attention as it enables properly coping major uncertainties, which are unsolved at the time of making decisions. Hence, valuing added flexibility in transmission investment portfolios, for instance, by investing in power electronic-based controller meanwhile transmission line projects are deferred, is necessary to make optimal upgrading. However, expressing the value of flexibility in economic terms is not a trivial task and requires new, sophisticated valuing tools, since the traditional investment theory has not recognized the implications of the interaction between the three aforementioned investment features. Any attempt to quantify investment flexibility almost naturally leads to the concept of Real Options (RO). The RO technique provides a well-founded framework -based on the theory of financial options, and consequently, stochastic dynamic programming- to assess strategic investments under uncertainty (Trigeorgis, 1996). 
In the first RO applications (Myers, 1977), valuation was normally confined to the investment options that can be easily assimilated to financial options, for which solutions are well-known and readily available (Rodriguez \& Rocha, 2006). Nevertheless, an investor confront with a diverse set of opportunities. From this point of view, investment projects can be seen as a portfolio of options, where its value is driven by several stochastic variables. The introduction of multiple interacting options into real options models highly increases the problem complexity, making the utilization of traditional analytical approaches unfeasible. However recently, simulation procedures for solving multiple American options have been successfully proposed. One of the most promising approaches is the Least Square Monte Carlo (LSM) method proposed by Longstaff and Schwartz (2001). LSM method is based on stochastic chronological simulation and uses least squares linear regression to determine the optimal stopping time (optimal path) in the decision making process.

This chapter lays out a general background about key concepts -uncertainty and risk- and the most usual risk management techniques in transmission investment are provided. Then, the concept of strategic flexibility is introduced in order to set its ability for dealing with the uncertainties involved in the investment problem. In addition, new criteria and advantages of the ROV approach compared with classical probabilistic choice are presented. A LSMbased method for decomposing and evaluating the complex real option problem involved in flexible transmission investments under uncertainties is developed.

The proposed methodology is applied to a study case, based on (Blanco et al., 2010a), which evaluates an interconnection reinforcement on the European interconnected power system, showing how the valuation of flexibility is a key task for making efficient and well-timed investments in the transmission network. The impact of two network upgrades on the system-wide welfare is analyzed within the proposed framework. These upgrades are the development of a new transmission line and the installation of a power electronic-based controller. Both upgrades represent measures to strengthen the German transmission network due to the fact that these are among the most important corridors within the Central Western European (CWE) region. Hence, a transmission project, which is currently under study, is compared to flexible investment in order to shed some light on the influence of the strategic flexibility on the optimal decision-making process. The research is focused on assessing the impact of the uncertainty of the demand growth, generation cost evolution and the evolution of the installed wind capacity on the decision-making process.

\section{Risks and uncertainties in the investment decision-making process}

According to Webster's dictionary, the word risk is defined as "possibility of loss or injury, someone or something that creates or suggests a hazard". Accordingly, risk is normally perceived in negative terms. In finance, the definition of risk is different and broader. Thus, risk refers to the probability of receiving a return on an investment different from expected return. Therefore, risk includes not only negative results, i.e. results that are lower than expected, but also positive results, i.e. returns that are higher than expected. In fact, it may refer to the former as downside risk and upside risk to the latter, but are considered both in the measurement of risk (Damodaran, 2002).

Thus, risk management procedures aim to develop a model to quantify the investment risk and then try to turn it into an opportunity that is necessary to compensate for the hazards. On the other hand, uncertainty is the randomness of the external environment. Investors cannot change their level. Uncertainty is an input into the valuation of investments. 
Exposure of an investment to uncertainty -the sensitivity of returns and the value of the investment against a source of uncertainty- is determined by a number of factors, including business line, the structure cost and nature of the markets of the investment. Through investment, the managers are able to change the level exposure of assets, with a resulting economic impact, the risk.

Thus, although in the literature uncertainty and risk are often used interchangeably, it is relevant to note the difference between them. Uncertainty refers to an unstructured collection of randomness and risk to the situation in which a result can be specified and may be assigned a probability of occurrence.

In general terms, there are variables involved in the valuation investment process whose evolution is gravitating to the generation of worth of the investment project. If these variables have uncertainties on their unfolding, it is generated a certain level of risk associated with the project value.

The identification and quantification of the project's risk must be obtained within the evaluation process. This risk assessment is fundamental for making optimal decisions as well as providing the needed inputs that properly replicate the uncertain behavior of the driving variables for conducting an active risk management throughout the project development.

\subsection{Implication of risk and uncertainty within the traditional decision tool}

Nowadays, markets require strategic decisions to invest in highly uncertain environments, characterized by the unknown of relevant aspects such as: market size, development costs or movements of the competing players. Therefore, there is currently a broad gap between what managers want to do and the capabilities of the available information and the decision tools (Olafsson, 2003).

In current decision tools, there are two main features that stand out as significant problems. The first one is that most of the tools require a forecast of future returns. Since the analysis often uses a single or point forecast, this is very subjective. Is this an overly optimistic projection of the defender of a project? , what are the growth rate and profit margin foreseen in the projection? In this context, managers consider often the forecast as reality, creating the illusion of certainty in relation to the results. To improve this, some practitioners try to extend the analysis to a set of projections or scenarios. These efforts seem sound knowledge to the authors, however, arbitrary to everybody else. Both, single stage or in the various scenarios, forecasting cash flow, under these conditions, becomes a subjective input (Damadaran, 2002).

The second problem of decision-making tools -most commonly used- is that future investment decisions are determined from the outset. Managers update and revise the investment plans, but the analysis, according to the structure of most of the tools, only includes the initial plan. Therefore, the world changes, but its model does not. As the gap between the tools and reality becomes bigger, the instruments are discarded, and important decisions are made in terms of strategic considerations and management expertise (Amran \& Kulatilaka, 1998).

Accordingly, alternative actions in response to changed conditions or new information, which emerge in the lifetime of the project are not accounted for. Commonly, the only decision made at the beginning is to go ahead with the project, or not. Thereafter management remains passive to a fixed operating strategy. Clearly, this approach is unsuitable in a competitive world, characterized by continuous change and uncertainty. 
Consequently, an efficient decision tool needs to take account of the volatility in project profits and remain flexible in response to unforeseen events (Olafsson, 2003).

\subsection{Risk and uncertainties in the worth creation}

Once the uncertainty and flexibility are explicitly included in the valuation of investments, there is a complete change of paradigms within the decision making process. From an active and strategic management of the uncertainties, one of the most important transformations in the way of visualizing a decision on an uncertain environment is derived: uncertainty creates worth. Consequently, by rethinking strategic investments, decision-makers must try to consider their markets taking into account the origin, history and evolution of the uncertainty, to determine the degree of exposure of their investments (how external events are reflected in profit and loss), then respond by positioning their investments, so that they can take full advantage of uncertainty.

From the traditional point of view, the higher the uncertainty level the lower value of the project. However, under an approach which manages the uncertainties actively and strategically, greater uncertainties may lead to higher asset value. For doing this, decisionmakers strive to identify and using their strategic options to flexibly respond to uncertainty developments.

An intuitive way to analyze this interaction between uncertainty and risk within the investment problem is by the see-saw investment metaphor. By visualizing the performance of an investment as a weighing-scale (Fig. 1), where the externalities are weighted according to the threats and opportunities of an investment, it could reveal the interaction between its final return range and the uncertainties. If it contemplates the uncertainty as the base of this scale, the level of risk -i.e. fluctuations around the expected return- clearly is constrained by the magnitude of the uncertainties that the investment is exposed to (Blanco, 2010b).

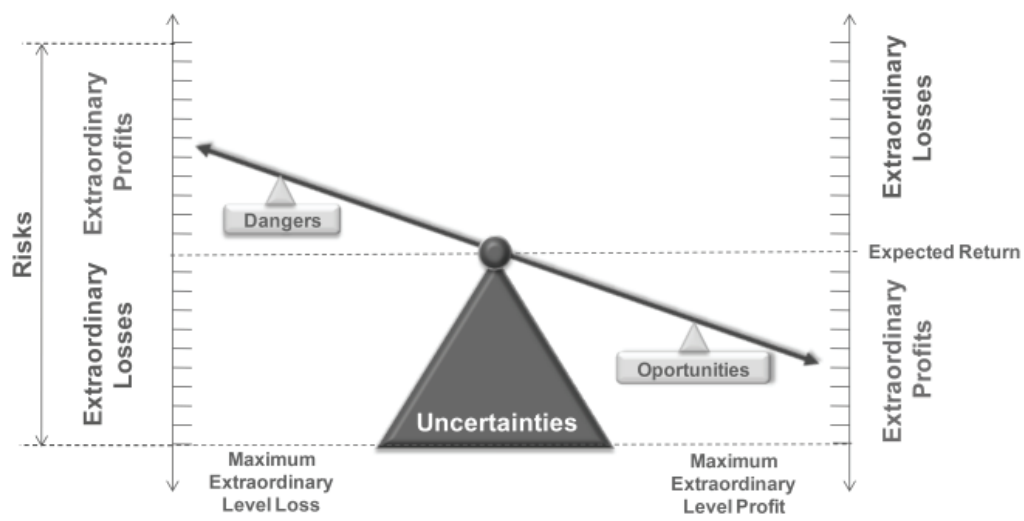

Fig. 1. Interaction between uncertainty and risk in investment performance

Therefore, if the investment is exposed to lower uncertainty, it would be exposed to lower extraordinary losses, but also, at the same time, would be less likely to seize extraordinary profits (Fig. 2). 


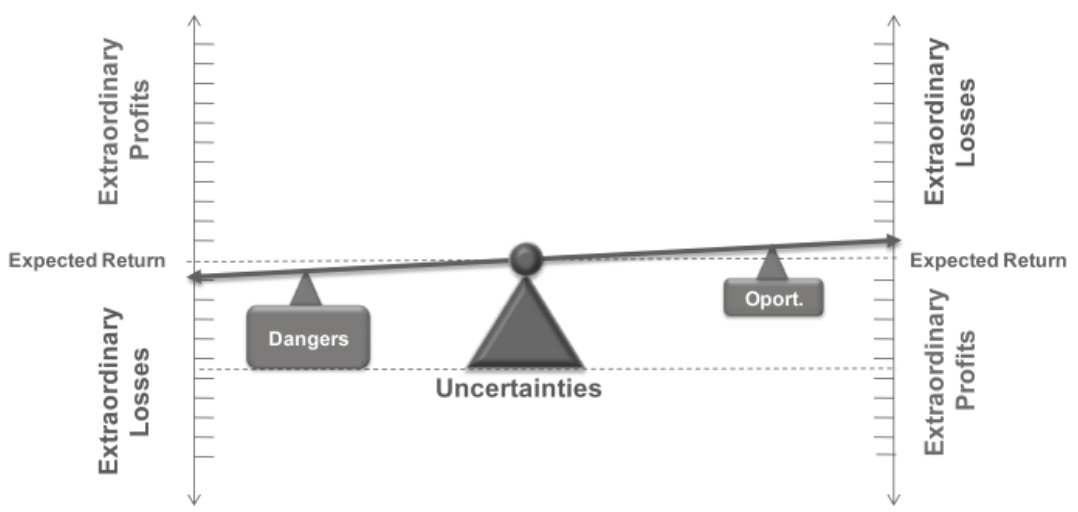

Fig. 2. Sensitivity of risk related to the uncertainties

However, the use of contingent claims (strategic flexibility of the investment) may limit the level of extraordinary losses, but remaining open a significant likelihood of extraordinary profits (Fig. 3).

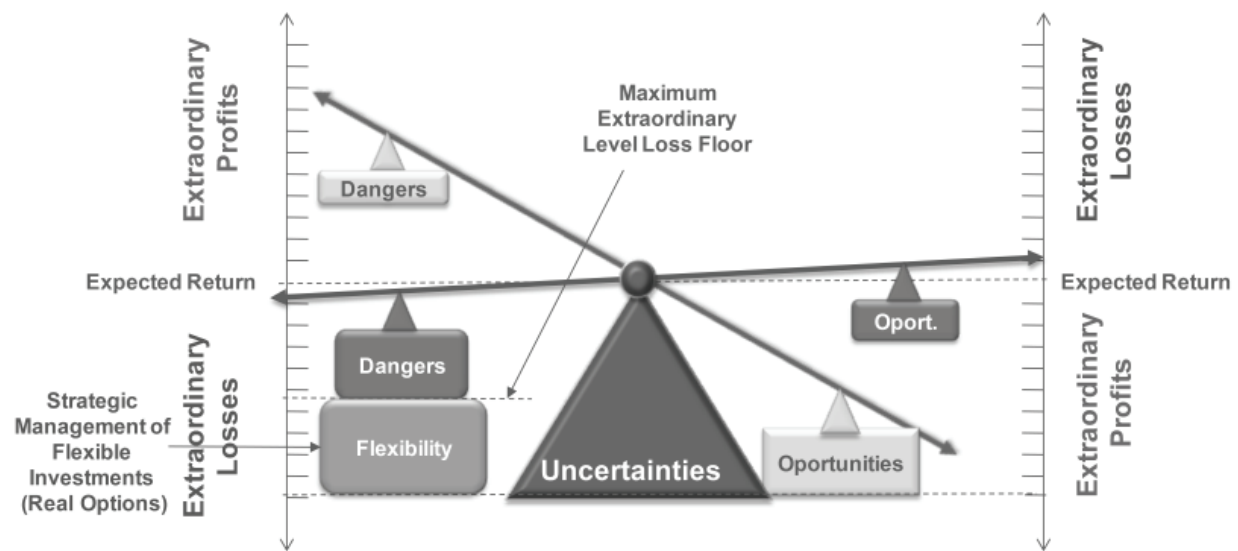

Fig. 3. Effect of Flexibility in the value of investments under uncertainty

Thus, through the optimal use of the flexibility of investments, it is possible to increase the value of the investment project with increasing uncertainties. Therefore, the key is flexibility in dealing with the uncertainties by having various options in place that can be exercised as new information emerges. The options derive their value from the fact that they establish a floor under possible project losses.

\subsection{Risk and uncertainties in the electric power system}

Nowadays, the risk analysis theory is widely used by decision-makers who face investment decision problems under uncertainty, since it provides a systematic and logical approach for the decision making process (Vásquez, 2009). In the context of restructuring the electricity supply business, the problem of valuing transmission system expansions could be 
addressed as a risk management problem (Blumsack, 2006), seeking to formulate a transmission expansion plan that led the planner to make adjustments in an easy, economic way for seizing opportunities or cutting losses according to the evolution of the uncertain variables.

Therefore, the uncertainties variables play a key role in the valuation of transmission investments, and consequently, their behavior should be properly replicated within the assessment models ${ }^{1}$. In what follows, the main uncertainties of transmission system expansion are briefly analyzed:

- Evolution of demand. The evolution of the electricity demand is a key variable heavily influencing the performance of transmission investments ${ }^{2}$. The uncertainty over its future evolution is often represented according to a growth rate of demand in each period of the analysis horizon.

- Generation costs. Most of the electricity generated worldwide is produced from one of the following primary energy carriers: coal, oil, gas, nuclear and renewable (hydro, wind, solar, etc.). No public markets or trading platforms exist for renewable, nuclear and hydro. On the other hand, there are market prices for coal, oil and gas, which could be subject to considerable fluctuations over the long-run ${ }^{3}$. Therefore, the main uncertainty over generation cost could be related to thermal-units. Many of these plants use fossil fuels as primary energy sources. Thus, generation costs can be closely correlated with the fuel prices. The significant volatility present in the fuel market makes this uncertainty relevant exerting a profound influence on investment decisions in the transport system.

- Discount rates. The discount rates usually allow transferring temporal cash flow to the present or future. From a financial point of view, these rates represent the returns expected by the investor, and are strongly related to their risk perception over a given project. Uncertainty over the discount rate can have two effects on an investment decision. First, random fluctuation in interest rates can enhance the expected value of a future payoff from investing. However, uncertainty over future interest rates can also lead to a postponement of investment. The reason is that uncertainty over futures discount rates creates a value to waiting for new information (to see whether interest rates rise or fall) (Dixit \& Pindick, 1994). Hence, there are two opposite effects of uncertainties over the discount rates, which should be carefully analyzed in order to make optimal investment decisions.

- Investment costs of transmission projects. The uncertainty in the evolution of prices of the raw material of the transmission equipment such as: steel, aluminium, copper and insulation has a considerable impact on investment costs in transmission projects and

\footnotetext{
1 The stochastic model of the uncertain variables of the transmission investment problem -taken into account in this chapter- is discussed in detail later.

2 Over the last years, electricity demand has grown only slowly in most developed countries. However, this growth has been far from certain and subject to stochastic fluctuations. Especially in the longer run, uncertainty on electricity demand growth has therefore also to be taken into consideration (Weber, 2004).

${ }^{3}$ For example, crude oil prices have risen by a factor of two between the beginning of 2007 and the middle of 2008, and have again dropped by factor of three at the beginning of 2009. The price of coal has not been more stable in comparison; it has varied by about a factor of three between 2008 and 2009. The factor for the same time-window for the natural gas is two (http:/ / tinyurl.com/27ns7ut).
} 
therefore affects decisions on expansion. It also was mentioned earlier that the costs of FACTS devices have a tendency to decrease, which must also be considered.

- Availability of system components. States of operation with unavailability of some components is frequent in the large-scale power systems. Therefore, they are relevant within the transmission investment assessment. The reason of this is that the price spikes, which appear in energy markets under perfect competition during deficit conditions, would provide, in theoretical terms, substantial revenues to attract the investment needed to ensure the optimal level of adequacy over the long-term. Notwithstanding, although these profits under deficit conditions are very significant, they occur infrequently and are very difficult to predict. This situation often encourages the investors, usually risk-averse, to postpone or discard investments that are needed for ensuring the adequacy of the system (Olsina et al., 2007). Therefore, these variables are relevant to investment analysis and should be considered.

Several approaches for assessing transmission investment have been proposed (Latorre et al., 2003), defining the evolution of the variables of the problem with certainty. These models are known as deterministic and represent the variables aforementioned by their expected values. These assumptions often make these models unsuitable for evaluating investment strategies in practice (Garver, 1970; Seifu et al., 1989; Romero \& Monticelli, 1994). There are also stochastic models that consider the random behavior of some input parameters ( $\mathrm{Yu}$ et al., 1999). However, there are only a few antecedents regarding the management of risk associated with financial performance, despite, its profound influence on the new market structures (Vásquez \& Olsina, 2007). Thus, the theory and tools for assessing transmission investments (TI) are still below the practical requirements of the new power markets. This is particularly true in aspects such as the transmission investment flexibility and the introduction of transmission controllers.

\section{Basic Net Present Value (NPV) calculations}

A classic NPV analysis works as follows. Let consider an immediate investment of $I_{0}$ today will generate cash flow $C_{j}$ for the next $\mathrm{n}$ years. As cash flow obtained in the future does not have the same value as cash flow received today, then future cash flow requires discounting. The discount rate represents the opportunity cost of capital, $k$ (Brealey, 2001).

$$
N P V_{0}=\sum_{j=1}^{4}\left(\frac{C_{j}}{\prod_{i=1}^{j}\left(1+k_{i}\right)}\right)-I_{0}=P V_{0}-I_{0}
$$

Generalizing;

$$
N P V=\sum_{j=0}^{N}\left(\frac{F F_{j}}{\prod_{i=0}^{j}\left(1+k_{i}\right)}\right)
$$


where $F F_{j}$ is the cash flow of the year $j$ and $N$ is the investment horizon. Note that in general, the discount rate may differ from year to year. This is considered by the subscripts in discount rates. As was aforementioned this rate equals the opportunity cost or the cost of capital of the company making the investment. Therefore, it should reflect the level of project risk. This rate is also known as hurdle rate, that is, a minimum acceptable rate of return for investing resources in a project.

\subsection{Flaws \& drawbacks of the NPV approach under uncertainties}

The net present value rule is implicitly based on some assumptions that are often overlooked. The most important is that either investment are entirely reversible 4 , that is, it can be undone and the capital outlays invested fully recovered if market conditions unfold unfavorably; or if it is irreversible, this is a proposition of a now-or-never opportunity, i.e. if the decision-maker does not execute the investment now, he will not be able to execute it in the future (Dixit \& Pindick, 1994).

Even though some investments fulfill these hypotheses, not all do. In practice, decisionmakers have the ability to adapt their investment strategies in response to undesired events, and therefore, limit the downside effects of the uncertainties. However, under the NPV framework, the only decision made at the beginning is to execute the investment, or not. Thereafter the decision-maker remains immovable to a fixed operating strategy.

Consequently, a major shortcoming the NPV approach is that these strategic options, which are often embedded into the project, are disregarded. Hence, contingent measures in response to changed conditions or new information, which emerge in the lifespan of the project, are simply overlooked.

The inevitable uncertainties associated with the transmission investments are better managed with investments that provide flexibility. As new information arrives, investors need the flexibility to alter operating strategies to seize favorable opportunities or to cut losses in the case of adverse scenarios. This flexibility may include various actions at different stages of the planning horizon, such as the options to defer, expand, reduce or even abandon the project. This flexibility to adapt to changing market conditions has a substantial value, which has to be considered when an investment implementation is being decided. It is thus essential that flexibility be properly quantified. Any attempt to quantify investment flexibility almost naturally leads to the notion of Real Options (Olafsson, 2003).

The ROV technique provides a well-founded framework-based on the theory of financial options- to assess strategic investments under uncertainty. It quantitatively takes into account investment risks and the value of the open options for planners. The next sections provide a detailed background about the option theory and its applications into the capital investment evaluations.

\section{Option valuations applied to flexible investments}

The paradigm behind the real option concept is simple and straightforward. On one hand, it is simple because there is a strong analogy between the options on financial assets and the opportunities to acquire real assets. On the other hand, straightforward, because the theory of valuing derivative assets in financial markets, option pricing theory, offers powerful tools

\footnotetext{
${ }^{4}$ Investment expenditures are sunk costs when they are firm or industry specific (Dixit \& Pindick, 1994)
} 
that can be applied to value real options accurately. The sense of real options lies on quantifying the worth generated by the intrinsic flexibility embedded into an investment project, thereby providing a correct basis for making strategic investment decisions (Brosch, 2001).

Strategic flexibility emphasizes the inherent asymmetry between gains and losses in the structure of a project. The real option concept extends the conventional (static) NPV approach by including the value associated with the flexibility inherent in a project. Therefore, the static NPV is augmented to become flexible NPV (Olafsson, 2003):

\section{Flexible NPV = Static NPV + Value of flexibility}

Since the value of flexibility always is positive, it adds value to the project; its value is the key concept in the real options approach. Therefore, the availability of these options will generally impact on the actual decision-making process, and consequently, must be fairly quantified.

\subsection{Financial options ${ }^{5}$}

An option is the right but not the obligation, to make a particular decision in the future. In general, one can say that the options are bilateral contracts by which a party pays a sum of money to another to acquire the right (option) to conduct a transaction (purchase and sale) or claim a specific sum of money in the future.

In this context, a financial option entitles the holder the right to buy or sell an asset at a specified price on or before a certain date. The set price is called the strike or exercise price and the date on or before which the right can be exercised is called maturity.

Financial options are a particular type of financial assets called derivative securities. The value of the derivative depends on the value of another asset on which is based on it, called the underlying asset. This means, the value of a derivative security derives from the value of another elemental asset.

There are essentially two different types of financial options. An option to buy -call optionentitles the holder to acquire an asset at a specified price on or before a certain date and the option to sell -put option- gives the holder the right to sell an asset at a specified price on or before a certain date.

In addition, financial options can be classified as American or European. When the option holder can exercise the option on a certain future date, it is implying that he can only use his right at that moment (on the date of expiry or maturity), and neither before nor after that, the derivative security is an European option.

Moreover, when the holder can exercise his contract until a specified future date, it means that the option holder can use his right until the expiration date; in this case, the financial option is an American option.

The holder of the right to exercise an option is said to have a long position (long position) in an option contract. The issuer (seller) of an option takes a short position (short position), and the obligation to buy or sell the asset (underlying) at the exercise price to or from the holder of the right (the long position), who should wish to take advantage of his rights.

Instead of buying the assets directly (i.e. take long position in the underlying), the investor can defer the investment by purchasing a call option to buy the asset at a later stage a certain

${ }^{5}$ This section closely follows (Olafsson, 2003). 
strike price. The holder of the option pays a premium to the call issuer for this entitlement. This premium is the price for the risk assumed by the issuer to take a short position (Olafsson, 2003).

A long position in an asset has a return (profit) profile, which is limited below by the price of the asset but has no upper limit. The profile of return for a long position in a call option, on the other hand, has a limit to the loss equal to the premium paid for the option. As long as the asset price rises above the purchase price there is gain, which increases linearly with the asset price. Similarly, when the price falls below the purchase price there is loss, which increases linearly with the dropping price. This is simply because the investor retains the asset.

The return profile for a long position in a call is quite different. When the asset price increases and exceeds the exercise price, it is said that the call option is in-the-money. If a call in-the-money is exercised, the gain (ignoring the premium) is given by the expression:

$$
I V_{L C}=\max (S-X, 0)
$$

where $S$ is the underlying asset price, $X$ the exercise price. The difference between both values is called the intrinsic value of the purchase option. Any increase in the asset price also leads to an increase in the intrinsic value of the option. However, before an option is exercised, the market value is generally higher than its intrinsic value. For this reason it is usually more profitable to sell the option instead of exercising it. This is an important point to be discussed in more detail later. If the underlying price falls below the strike price, outthe-money, the intrinsic value of the call also falls, but only to the floor set by the premium paid for the long position. In other words, the premium is the maximum loss that a long position in a call may suffer.

\subsection{Real options}

Real options are based on the concepts of financial options discussed in the previous section. The real option approach applies financial option theory to theories of decision making for investment in capital projects.

The traditional NPV approach does not seize the intangible aspect of these high-risk investments with potential extraordinary returns. Hence, the key issue is the use of the available options, to set a lower limit to potential losses while the possibility of these profit remaining open. In fact, a firm may have a portfolio of options which defines its performance profile. The real options approach can therefore be extended to a portfolio management of the underlying project together with all available flexibility options. Some examples of the possible options are presented below.

According to Copeland et al. (2003), real options can be classified into:

Postponement option: It represents the right of an owner to postpone an investment for a period of time while waiting for new information that arrives to the market. In exchange for this, the decision-maker rejects the cash flow that would generate the project on the future, if it is executed immediately. From a financial point of view, it can be interpreted as an American call option.

Abandonment Option: It allows ending activities and selling off assets that originally composed the capital investment (plant and equipment). This option is analogous to an American put option with a strike price equal to the scrap value of the project. 
Expansion or growth option: It allows expanding production capacity and/or accelerating the use of available resources, if the market conditions that occur after one has performed some initial investment, are more favourable than expected. This option is equivalent to an American call option.

Reduction or contraction option: This option provides the holder the right to reduce the size of operations if conditions are unfavourable; a project which can be reduced is more worth than the same project without that opportunity. Financially, it is equivalent to an American put option.

Extension or pre-cancellation option: It is the possibility to extend (reduce) the lifespan of an asset or the term of a contract by the payment of some monetary amount. The extension option is equivalent to an American call option while the possibility of shortening is analogous to a put American type.

Switch option: It offers the possibility of using the same assets and inputs to produce different products. Furthermore, it is available when an alternative is to change the primary inputs without altering the final product. These options are equivalent to a portfolio of financial options with both call and put American options.

Closing and reopening option: It provides the ability to stop and restart the operation of a project according to market conditions. Restart operations that previously have been turned off is equivalent to an American call option. Cancelling initiated operations previously, it is equivalent to an American put option.

\section{Real options valuation}

Different methods were developed to value financial options but their applications in the real options setting are conditioned to the particular characteristics of each problem. In practice, the underlying assumptions of traditional option valuation methods often do not hold when assessing capital investment projects. There are three general solution methods:

Stochastic differential equations: This method solves a partial differential equation (PDE). It mathematically expresses the dynamics of the option value for specific conditions. The analytic solution of the PDE provides the option value as a direct function of the inputs. The Black-Scholes's equation is the best known analytic formulation (Black \& Scholes, 1973).

A major advantage of this analytical solutions is that there are many available tools and algorithms are quite fast.

A disadvantage is that computational complexity increases as more sources of uncertainty are incorporated. Furthermore, it usually works as a black-box, making it difficult to interpret the consequence and effects of the contingent decisions.

Stochastic dynamic programming: As it shown by Dixit \& Pindick (1994), dynamic programming is a very useful approach for dynamic optimization problems under uncertainties. It decomposes a whole decision sequence into two components: the immediate decision and a valuation function that encapsulates the consequences of all subsequent decisions, starting with the position that results from the immediate decision.

The more popular method is the binomial lattice, introduced by Cox et al. (1979).

The advantages of the binomial lattice are: it can analyze a large number of applications of real options; it is practical because it retains the appearance of the analysis of discounted cash flow; uncertainty and contingent consequences of decisions are described in a natural way; therefore, the model binomial generates a good picture of the problem and the decision can be easily traced. 
The disadvantages of binomial trees are: the method is developed based on a number of assumptions and these should be fulfilled by the options discussed. The most important assumptions are: perfect financial market; possibility of buying or selling short; constant short-term risk-free interest rate throughout the period under analysis; perfectly divisible assets; changes in the underlying asset price according to a multiplicative binomial process that follows a GBM (probability distribution of the underlying lognormal and the volatility grows linearly with time).

Stochastic simulation models: In this case the model takes several possible paths of the underlying asset evolution into account from current date to the moment of decision. The commonly used method is Monte Carlo simulation. At the end of each path, the optimal investment sequence for this particular realization can be obtained, and the income of the project can be calculated.

As it was aforementioned, the advantages of Monte Carlo simulation method are: it can handle various aspects of real world applications, allows direct processing of all types of assets, whatever the number and kind of stochastic behavior of the sources of uncertainties. In addition, including new source of uncertainty is much simpler than in the case of other numerical models. The disadvantage inherent in the implementation of this method is that it requires a large amount of calculations, which involves extensive computing resources and is quite expensive in computation time. However, this disadvantage is being overcome daily with the progress of software and hardware.

\subsection{Least Square Monte Carlo (LSM) method}

In the early stages of the ROV, valuation was normally confined to the options for which solutions of the financial could directly be applied. This was done mainly using few underlying assets and simple options with European features or American perpetual options (Rodriguez \& Rocha, 2006). However, an investor is normally confronted with a vast opportunity set. Hence investment projects are a portfolio of options; frequently depending on several stochastic variables.

The introduction of multiple interacting options into the real options models substantially increases the difficulty of solving them, making traditional numerical approaches inadequate. Nevertheless, simulation procedures for successfully solving multiple American options have been proposed. One of the most promising approaches is the Least Square Monte Carlo (LSM) method proposed by Longstaff and Schwartz (2001).

LSM method is based on Monte Carlo simulation and uses least squares linear regression to determine the optimal stopping time in the decision making process. Moreover, this approach has proven to be a very intuitive and flexible tool.

The value of an American option, with a state variable $X_{\tau}$, payoff $\Pi\left(\tau, X_{\tau}\right)$ where $\Pi$ is a known function ${ }^{6}$, and that can be exercised from $t$ until maturity $T$, is equal to:

$$
F\left(t, X_{\tau}\right)=\max _{\tau \in T}\left\{\mathbb{E}_{t}^{*}\left[\Pi\left(\tau, X_{\tau}\right) \cdot(1+\rho)^{-(\tau-t)}\right]\right\}
$$

\footnotetext{
${ }^{6}$ In formal mathematical terms, $\Pi \in \mathcal{L}^{2}(\Xi, \mathcal{F}, \mathbb{Q})$ is the space of square-integrable functions with respect to $\mathbb{Q}$, where $\Xi$ represents the space of all feasible states of the economy, $\mathcal{F}$ is the filtration generated by the state variables and $\mathbb{Q}$ is the equilibrium probability measure on $\mathcal{F}$.
} 
where $\tau$ is the optimal stopping time $(\tau \in[t, T])$ and the operator $\mathbb{E}_{t}^{*}[$.$] represents the risk$ neutral expectation conditional on the information set available at $t$. The discount factor between any two periods is $d f=(1+\rho)^{-1}$, where $\rho$ is the risk adjusted discount rate.

As is exposed in (Rodriguez \& Rocha, 2006), the LSM approach proposed a Monte Carlo simulation algorithm to estimate the option value stated in (Cortazar et al., 2006). Eq. (4) can be expressed in a discrete time splitting the maturity time $T$ in $N$ discrete intervals. Then, sample paths of the underlying asset stochastic evolution are generated by means of Monte Carlo simulation techniques.

It is assumed that the option can only be exercised in discrete times into a restricted set of dates: $\left[t_{0}=0, t_{1}=\Delta t, \cdots, t_{N}=N . \Delta t=T\right]$. The optimal stopping policy -along the path $\omega$ - can be derived by applying the Bellman`s principle of optimality: "An optimal policy has the property that, whatever the initial action, the remaining choices constitute an optimal policy with respect to the sub-problem starting at the state that results from the initial action" (Dixit \& Pindick, 1994). This statement can mathematically be expressed as follows:

$$
F\left(t_{n}, X_{t_{n}}\right)=\max \left\{\Pi\left(t_{n}, X_{t_{n}}\right), \mathbb{E}_{t_{n}}^{*}\left[F\left(t_{n+1}, X_{t_{n+1}}\right)\right] \cdot d f\right\}
$$

By using this equation, we can determine the path-wise optimal policy, restricted to the given dates, by comparing the continuation value,

$$
\Phi\left(t_{n}, X_{t_{n}}\right)=\mathbb{E}_{t_{n}}^{*}\left[F\left(t_{n+1}, X_{t_{n+1}}\right)\right] . d f
$$

with the payoff $\Pi\left(t_{n}, X_{t_{n}}\right)$. Hence, the optimal stopping time for the $\omega$-th realization, is found, beginning at $T$ and working backwards, applying the following condition:

$$
\text { if } \Phi\left(t_{n}, X_{t_{n}}(\omega)\right) \leq \Pi\left(t_{n}, X_{t_{n}}(\omega)\right) \text { then } \tau(\omega)=t_{n}
$$

At the maturity time, the options are no longer available, therefore, the continuation value equals zero $\left(\Phi\left(T, X_{T}\right)=0\right)$, consequently $(8)$ holds as long as the payoff value is positive. Prior to $T$ at $t_{n}$, the option holder must compare the payoff obtained from the immediate exercise $\left(\Pi\left(t_{n}, X_{t_{n}}(\omega)\right)\right)$ with the continuation value $\left(\Phi\left(t_{n}, X_{t_{n}}(\omega)\right)\right)$. When the decision rule (8) holds the stopping time is updated. Finally, $\left(\tau(\omega)=t_{n}\right)$ the value of the American option is then calculated as the average of the values over all realizations (Longstaff \& Schwartz, 2001):

$$
F(0, x)=\frac{1}{\Omega} \sum_{w=1}^{\Omega} \Pi\left(\tau(\omega), X_{\tau(\omega)}\right) \cdot(1+r)^{-(\tau(\omega))}
$$

Then, the problem reduces to one of finding the expected continuation value at $\left(t, X_{t}\right)$, in order to apply the rule (8). Here is where the LSM method makes its main contribution. This method estimate the continuation for all previous time-stages by regressing from the discounted future option values on a linear combination of functional forms of current state variables. Considering that the functional forms are not evident, the most common implementation of the method is simple powers of the state variable (monomial) (Longstaff \& Schwartz, 2001). 
As exposed in (Cortazar et al., 2006), let define $L_{j}$, with $j=1,2, \ldots, J$ as the orthonormal basis of the state variable $X_{t}$ used as regressors to explain the occurred present value in the $\omega$-th realization, then the least square regression is equivalent to solve the following optimization problem:

$$
\min _{\varphi} \sum_{w=1}^{\Omega}\left[\Pi\left(t+1, X_{t+1}(\omega)\right) \cdot d f-\sum_{j=1}^{J} \varphi_{j} L_{j}\left(X_{t}(\omega)\right)\right]^{2}
$$

Then the resulting optimal coefficients $\varphi^{*}$ from solving (10) are utilized to estimate the expected continuation value $\Phi^{*}\left(t, X_{t}(\omega)\right)$ applying the following expression:

$$
\Phi^{*}\left(t, X_{t}(\omega)\right)=\sum_{j=1}^{J} \varphi_{j}^{*} L_{j}\left(X_{t}(\omega)\right)
$$

Working backwards until $t=0$, the optimal decision policy on each sample path -choosing the largest between the immediate exercise and the expected continuation value- can be determined. Finally, by applying (9) the value of the American option can be computed. Fig. 4 represents the process described for an individual deferral option for two periods. Recently, Gamba (2003) proposed a model which extending the LSM approach decomposes complex multiple real options (with interacting options) into simple hierarchical sets of individual options. The decomposition principle can be used by applying any kind of methodology based on dynamic programming and Bellman equation (Cortazar et al., 2006).

\subsection{Multi-option investment problems}

As mentioned before, Gamba(2003) has presented an extension of the LSM method to value independent, compound and mutually exclusive options. According to that approach, options can be classified as (Rodriguez \& Rocha, 2006):

Independent options: The value of a portfolio comprising only independent options is equal to the sum of each individual option value, computed by the LSM method. Only in this situation, the additivity property holds, even when the underlying assets might not be independent.

Compound options: Let a portfolio of $H$ compounded options, where the execution of $h$-th option creates the right to exercise the subsequent $(h+1)$-th option. A typical example of this kind of sequential options is the right to expand capacity, which is just originated when the initial investment option is exercised. The payoff $\Pi_{h}\left(t, X_{t}\right)$ of the $h$-th option, must take into account the value of the option $(h+1)$-th. These options can be valued by applying the LSM approach. Consequently, the value of the $h$-th option is calculated according to:

$$
F_{h}\left(t, X_{t}\right)=\max _{\tau \in\left[t, T_{h}\right]}\left\{\mathbb{E}_{t_{n}}^{*}\left[\Pi_{h}\left(\tau, X_{\tau}\right)+F_{h+1}\left(\tau, X_{\tau}\right)\right] . d f\right\}
$$

The Bellman equation for a set of sequential real options can be formulated as following:

$$
F_{h}\left(t_{n}, X_{t_{n}}\right)=\max \left\{\begin{array}{l}
\Pi_{h}\left(t_{n}, X_{t_{n}}\right)+F_{h+1}\left(t_{n}, X_{t_{n}}\right), \ldots \\
\mathbb{E}_{t_{n}}^{*}\left[F_{h}\left(t_{n+1}, X_{t_{n+1}}\right)\right] . d f
\end{array}\right\}
$$




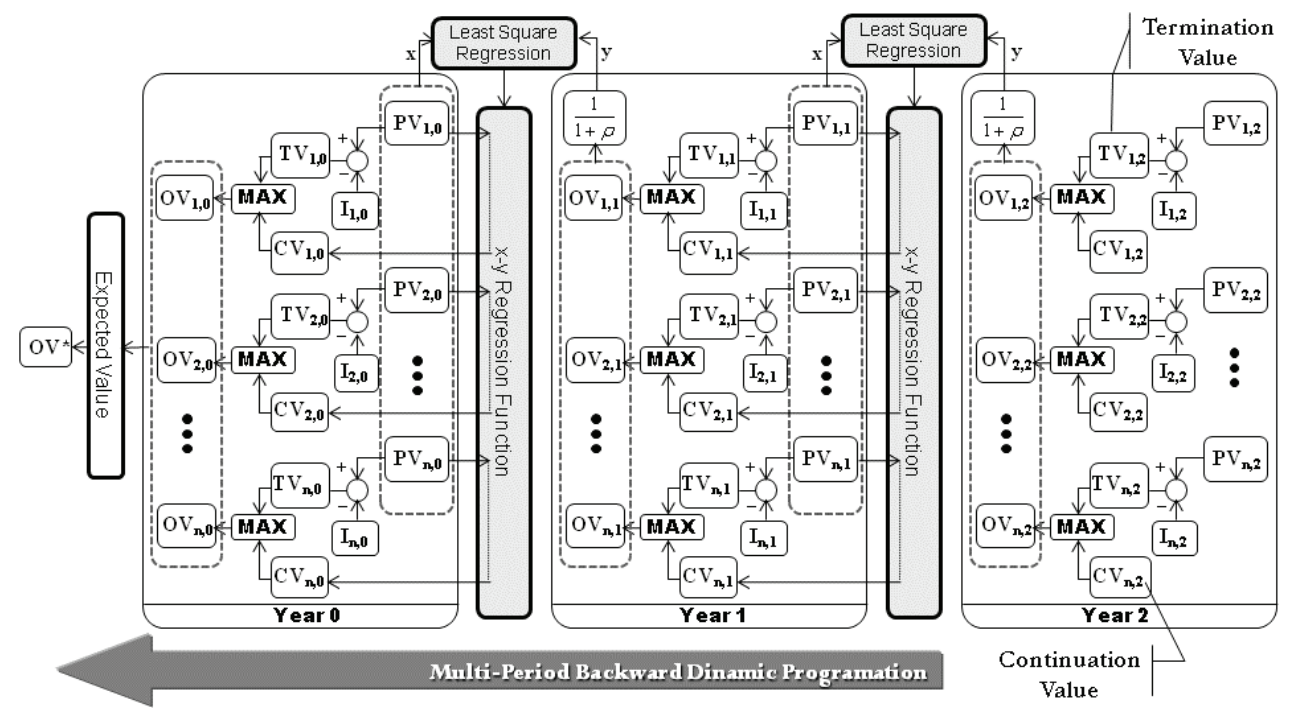

Fig. 4. Optimization of exercising time of an option to defer investment using LSM

Mutually exclusive options: A set of options are mutually exclusive when the exercise of one of them eliminates the opportunity of execution of the remainder. The expansion and abandon options are common examples of mutually exclusive options. Thus, the problem is extended to find both the optimal stopping time and optimal option to be exercised. Therefore, the control variable is a bi-dimensional variable $(\tau, \zeta)$, where $\tau$ is a exercising time in $\left[t, T_{h}\right]$ and $\zeta \in\{1,2, \ldots, H\}$. The value of the option, choosing the best among $H$ mutually exclusive options, is:

$$
G\left(t, X_{t}\right)=\max _{(\tau, \zeta)}\left\{\mathbb{E}_{t_{n}}^{*}\left[F_{\zeta}\left(\tau, X_{\tau}\right)\right] . d f\right\}
$$

Thus, the Bellman equation of a portfolio of mutually exclusive options is given by:

$$
G_{h}\left(t_{n}, X_{t_{n}}\right)=\max \left\{\begin{array}{l}
F_{1}\left(t_{n}, X_{t_{n}}\right), \cdots, F_{H}\left(t_{n}, X_{t_{n}}\right), \cdots \\
\mathbb{E}_{t_{n}}^{*}\left[G_{h+1}\left(t_{n+1}, X_{t_{n+1}}\right)\right] . d f
\end{array}\right\}
$$

Each $F_{h}\left(t_{n}, X_{t_{n}}\right)$ and the continuation value $\left(\Phi_{n}\right)$ is estimated by the LSM approach as explained before.

\section{Decision making of flexible investment portfolios in transmission system}

This section addresses the problem of assessing flexible transmission investment portfolios under uncertainty on the basis of the social welfare of the electricity market. It proposes a methodology based on the real options approach for valuing the flexibility of strategic investments in the transmission network and finding the optimal timing of the execution of the investment alternatives. 
Within this model, the research work develops a suitable approach for assessment of Transmission Investment Portfolios (TIPs) considering Flexible Alternative Current Transmission Systems (FACTS) devices. FACTS are power electronics-based devices for the control of voltages and/or currents, enhancing controllability and increasing power transfer capability (Zhang et al., 2006). In addition, FACTS could add flexibility to the investment portfolio through new strategic options such as relocation and abandon.

The evolution of fundamental uncertain variables is modelled through appropriate stochastic processes. Some of these are:

- power demand growth,

- power generation costs,

- $\quad$ penetration level of renewable generation.

The reduction of the system costs incurred for serving the load demand over the optimization horizon is used as the measure to evaluate the economic performance of the proposed network upgrades.

Under this framework, the value of a TIP is defined by the increase (or decrease) of the social welfare resulting from executing the investments considered in the portfolio. Taking into account an inelastic demand, the incremental social welfare should be quantified through the generation cost savings between the base scenario (BS, without investment) and the investment scenario (IS, with the investment executed).

\subsection{Stochastic simulation of the transmission investment in power market}

The study case analyzes aims to present a method for assessing flexible investments in a reduced European interconnected transmission system model under uncertain scenarios.

This section takes FACTS devices into account again, which add flexibility to the investment portfolio through new strategic options such as relocation and abandonment. These investment alternatives are evaluated according to the Real Option method by applying the LSM approach.

The proposed methodology is applied in a study case which evaluates a reinforcement at the German transmission network, by showing how the valuation of flexibility is a key task for making efficient and well-timed investment in the transmission network.

This study case is an extension of the paper (Blanco et al., 2010a), incorporating the model of an uncertain cumulative growth of the installed wind capacity according to a stochastic logistic growth law.

Moreover, the stochastic behaviour of system components, demand growth and generation cost evolution is simulated through the Monte Carlo method. In order to determine the operation cost for each hour of the investment horizon under the BS and the IS, an Direct Current Optimal Power Flow (DC-OPF) model is applied. The cost difference between both scenarios defines the underlying asset.

The OPF model has been widely used in many pool-based deregulated electricity markets to calculate the generation dispatch based on the bids submitted by generators and loads, also taking into account the network constraints.

Normally, the objective is to maximize the social welfare or to minimize the generation cost if loads are inelastic. Evidently, the OPF calculation often neglects some characteristics of the real market behaviour within the regarded system. For instance, national borders and the respective cross-border trading cannot be regarded explicitly but is incorporated by the capacity limits of the lines. 
The advantage of the OPF calculation is that the results represent the true value of network upgrades irrespective of the actual market behaviour (Blanco et al., 2010a).

Thus, the optimization problem can be mathematically formulated as follows:

$$
\begin{aligned}
& \min \left[\sum_{i} \sum_{g} C_{g}\left(P_{g}^{i}\right)\right] \\
& \text { s.t. }\left\{\begin{array}{l}
\text { a) } \sum_{g} P_{g}^{i}-\sum_{d} P_{d}^{i}-\sum_{l} F_{l}^{i}=0 \\
\text { b) } P_{g}^{i, \min } \leq P_{g}^{i} \leq P_{g}^{i, \max } ; F_{l}^{\min } \leq F_{l} \leq F_{l}^{\max } \\
\text { c) } P_{F, i}+\frac{X_{T C S C}^{\max }}{X_{i j} \cdot\left(X_{i j}-X_{T C S C}^{\max }\right)} \geq 0 ; \\
\text { d) } P_{F, i}+\frac{X_{T C S C}^{\min }}{X_{i j} \cdot\left(X_{i j}-X_{T C S C}^{\min }\right)} \leq 0
\end{array}\right.
\end{aligned}
$$

where $C_{g}$ is the supplier bid curve as well as $P_{g}^{i}$ and $P_{d}^{i}$ are the power generated and demanded by unit $g$ and load $d$, respectively at node $i$. The power flow through all transmission lines connected to node $i$ is denoted by $F_{l}$. The operation limits of each generator unit are stated by $P_{g}^{i, \min , \max }$ and the network restrictions are set by $F_{l}^{\min , \max }$.

This research analyses the FACTS devices called Thyristor Controlled Series Compensator (TCSC) under steady state operation For static implementations, these FACTS devices can be modelled by power injection models (PIM) (Wang et al., 2002). The PIM model depicts FACTS as devices that inject a certain amount of active and reactive power into its nodal connections; meaning that this controller operation is replicated by these injection flows. Constrains c) and d) are related to this model of operation of the FACTS devices connected between the nodes $i$ and $j$.

The stochastic behaviour of the power market model contemplated in this chapter can be defined as a fundamental or bottom-up model, since annual generation costs are directly influenced by the long-term stochastic movements of the uncertain variables. Hence, a several realizations are necessary to conduct Monte Carlo simulations with accurate statistical estimations.

From the economical point of view, the stochastic cash flow, defined by the annual generation cost saving for each realization, is applied in order to evaluate the performance of the transmission investment. Setting the investment cost and discount rate, stochastic discounted cash flow calculations are performed. Finally, real option techniques are applied for adding the flexibility value of each investment alternative, and the optimal investment decision is pointed out.

\section{Load growth modelling}

The growth of the electricity demand is a key variable largely influencing the performance of transmission investments. This growth of electricity demand is stochastic by nature. Certainly, climate changes, acceleration and downturns of the economic cycle as well as population dynamics turn random deviations out around the long-run expected value of the growth rate (Olsina et al., 2006). 
These random deviations of the growth rate around the expected values of the annual drift, interpreted as an error of forecasted growth, are commonly assumed to be Gaussian according to the Central Limit Theorem- by following a generalized Wiener process. This process might be formulated as shown below:

$$
d w=\varepsilon \sqrt{d t}
$$

where the variation in the variable $w$ during a short period $\Delta t$ is defined by the product of a random variable and the square root of the period length. $\varepsilon$ is so-called white noise, i.e. a random variable which has a Gaussian distribution with an expected value equal to 0 and a variance of 1 . A Wiener process can be classified as a particular form of a Markov-process, i.e. it is a stochastic process, where the current value contains all the information retrievable from the random variable wander (Weber, 2004).

Then, the stochastic model of the demand growth rate can be represented by a generalized Brownian Motion (BM) according to the following expression:

$$
d R_{j}(t, n)=\mu_{R}(t, n) \cdot d t+\sigma_{R}(n) \cdot d w
$$

Thereby the estimated unconditional mean load growth rate at the $n$-th node, at the instant $t$ is $\mu_{R}(t, n) ; \sigma_{R}(n)$ is the estimated unconditional standard deviation for this period and $d w$ is the Wiener process.

Within this work, the demand growth of the German power system is taken as an uncertain variable. The demand growth within the other regarded countries are taken as covered by new local generation, this is due to the lack of information about the generation capacity expansion in those countries. Nevertheless, a stochastic fluctuation around this null growth is taken into account, representing the possible inability of new generation entrance. The parameters used into the stochastic process are exposed in (Blanco et al., 2010a).

\begin{tabular}{|c|c|c|c|c|}
\hline Country & $\begin{array}{c}\mu_{L_{i}}^{\text {peak }}(0) \\
{[\%]}\end{array}$ & $\sigma_{L_{i}}^{\text {peak }}$ & $\begin{array}{c}\mu_{L_{i}}{ }^{\text {base }}(0) \\
{[\%]}\end{array}$ & $\sigma_{L_{i}}{ }^{\text {base }}$ \\
\hline Germany & 1.5 & 0.15 & 1.5 & 0.1 \\
\hline $\begin{array}{c}\text { Benelux } \\
\text { countries }\end{array}$ & 0 & 0.1 & 0 & 0.1 \\
\hline
\end{tabular}

Table I. Demand Growth Parameters (ENTSO, 2009).

\section{Generation cost modelling}

The main impact of a transmission investment on the social welfare is reflected as generation cost savings by bringing down the network-related system operational costs such as out-of-merit generation costs caused by network bottlenecks. Fluctuations of the transmission investment performance, according to this benchmark, are mainly related to generation cost fluctuations of the thermal units, which are strongly correlated with their own fuel prices. Commonly, the average marginal cost of generation of the unit generator $g$ at each instant $t$, denoted as $\overline{M C_{g}}(t)$, can be derived from the average thermal efficiency $\bar{\eta}_{g}(t)$ and the prevailing fuel prices $p_{g}^{F}$ at that moment: 


$$
\overline{M C}_{g}(t)=\frac{p_{g}^{F}(t)}{\overline{\eta_{g}}(t)}
$$

Therefore, the uncertainty over the generation cost savings are strongly linked with fuel price uncertainties. A reasonable and realistic way to replicate the uncertain evolution of the fuel prices is through a mean-reverting stochastic process. A mean-reverting process is one where the stochastic paths evolve fluctuating around a known long-run mean. The simplest mean-reverting process, called Ornstein-Uhlenbeck stochastic process, is expressed below:

$$
d\left(\ln p_{g}^{F}(t)\right)=\alpha\left(\ln \overline{p_{g}^{F}}-\ln p_{g}^{F}(t)\right)+\sigma^{\ln p_{g}^{F}(t)} d W
$$

where $\alpha$ is the speed of reversion to the mean, $\sigma^{\ln p_{g}^{F}(t)}$ is the volatility of natural logarithmic of fuel prices, and $\overline{p_{g}^{F}}$ is the normal level of the natural logarithmic of fuel price $p_{g}^{F}(t)$, i.e. the level to which $p_{g}^{F}$ tends to revert.

Within this work, the stochastic paths of fossil fuel prices are simulated according to the exposed process. The historical as well as the forecast data (IER, 2009) on costs and prices have been used to estimate the numerical parameters of Eq. 19. These parameters are listed in Table II. In the simulations, nuclear fuel cost prices are assumed constant over the time horizon. The main fundamental of this assumption is based on the fact that the uranium cost is only a small fraction of the total variable cost (around $5 \%$ ) in nuclear plants and the deviations around the expected value are quite narrow in comparison to the fuel price fluctuations (Webber, 2005). Furthermore, nuclear power stations seldom are the marginal units setting the market clearing price.

\begin{tabular}{|c|c|c|c|}
\hline Fuel Type & $\begin{array}{c}p_{g}^{F}(0) \\
€ / \mathrm{MW}\end{array}$ & $\begin{array}{c}\overline{p_{g}^{F}} \\
€ / \mathrm{MW}\end{array}$ & $\sigma^{\ln p_{g}^{F}(t)} \%$ \\
\hline Gas & 12.46 & 17.94 & 0.129 \\
\hline Oil & 20.99 & 28.21 & 0.3 \\
\hline Coal & 5.51 & 6.64 & 0.14 \\
\hline
\end{tabular}

Table II. Mean Reversion Process Parameters

\section{Network model}

The optimal power flow calculations are performed on the reduced network model presented in (Blanco et al., 2010a), which is built in order to replicate realistic scenarios of the transmission system in the Central Western European (CWE) region (Belgium, France, Germany, Luxembourg, and the Netherlands). Nodes are also modelled in Austria, the Czech Republic, Poland, and Switzerland in order to taking possible loop-flows into account. The detailed characteristics of the network model and the data which have been used are presented in (Waniek et al., 2009). Figure 5 gives a general view of the configuration of the network model. Within Germany, 31 nodes are allocated to the 16 federal states. This data is useful as relevant statistical informations are often divided up into the federal states. These statistics include current and expected values of installed capacity in renewable energies like wind energy, photovoltaics, biomass, etc. as well as the use of combined heat and power. The large conventional power plants are explicitly allocated to the network nodes utilizing a detailed data base. 
The model accuracy of the other regarded regions and markets is nearly the same as for Germany although the focus of the entire model is the implications for the German market and the transmission system. The numbers of nodes of the other regions are the following: Belgium: 4 nodes, France: 13 nodes and, The Netherlands: 9 nodes.

In addition, the feed-in from conventional power plants and its future development is crucial in order to replicate possible future congestions. A detailed dataset of the power plants in the modelled regions presented in (Blanco et al., 2010a) is utilized for the present situation. The included units can be differentiated by installed capacity, fuel type, and age. These units are assigned to the nodes of the sample network using geographical information.

The net generating capacity of the conventional power plants in Germany is almost constant until 2020 by raising capacities of hard coal and natural gas-fired plants. This is mainly due to the closure of nuclear plants which is currently under discussion and could end up being postponed. In addition, the use of renewable energies, especially wind energy, is expected to increase further. The intermittent in-feed is modelled with different situations which are explained later on.

Regarding the pumping storage plants, the complexity in the modelling of these units results from the interdependency of the pumping and generating process. Units without any natural inflow can only generate that amount of electricity that was stored before, taking into account the limited process efficiency. Within the presented approach, this problem is solved by a sequential simulation of the base load situation first, followed by the peak load situation. During the different base load situations, the pumping storage units are considered as dispatchable loads in the OPF. Depending on the price, a certain amount of electricity is stored in the reservoir. The assumed size of the reservoir results from the assumption that every unit is able to generate maximum power during all peak load hours. The formal formulation of this approach can be founded in (Blanco et al., 2010a).

\begin{tabular}{|c|c|c|c|c|}
\hline & 2007 & 2010 & 2015 & 2020 \\
\hline Nuclear & 20.5 & 16.5 & 13.0 & 1.3 \\
\hline Lignite & 20.5 & 22.6 & 22.0 & 22.0 \\
\hline Hard Coal & 30.5 & 33.0 & 34.6 & 32.8 \\
\hline $\begin{array}{c}\text { Natural } \\
\text { Gas }\end{array}$ & 25.3 & 27.8 & 33.6 & 42.8 \\
\hline Total & 96.8 & 99.9 & 103.4 & 98.9 \\
\hline
\end{tabular}

Table III. Development of the power plant mix in Germany (in GW)

\section{Wind scenarios}

Two demand scenarios (base load and peak load) and three wind situations are regarded, in order to reduce the number of calculated situations for each realization and each year. The probability of each wind situation occurring is determined according to the empirical histogram shown in Fig. 6.

The underlying data are actual values of the wind feed-in in Germany during 2006 in a 15 minute resolution.. The histogram is split into three sections. The first region on the lefthand side, low wind, covers $50 \%$ of all values. The next $30 \%$ of the values are in the second region, medium wind, and the third $20 \%$ correspond to a high wind condition. 


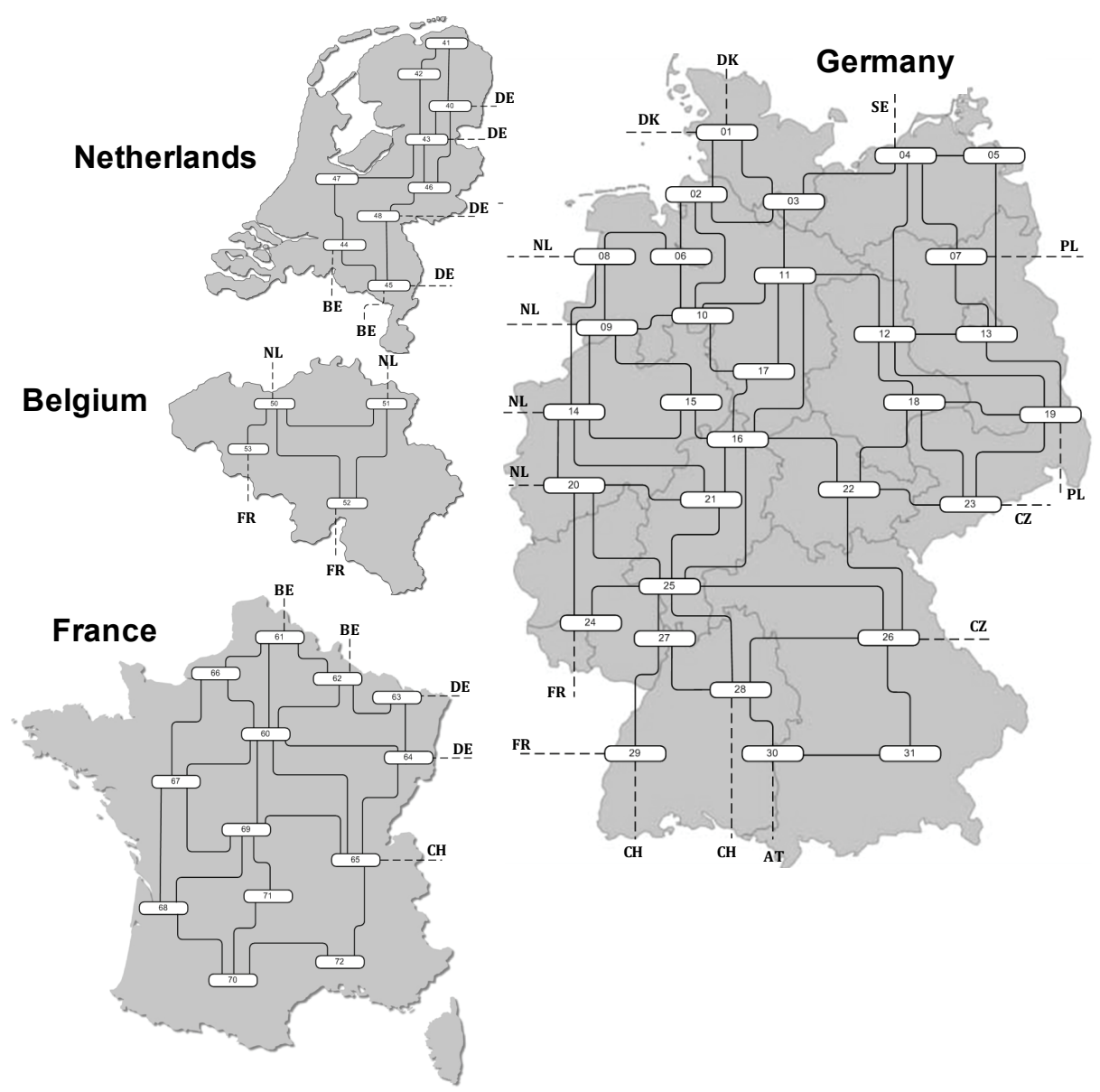

Fig. 5. Structure of the network ENTSO-E model (Waniek et al., 2009)

Hence, the wind feed-in that is used in the calculations is defined as the median in these three sections. The matrix shown in Table IV of the six possible combinations is obtained under the assumption that $70 \%$ of the year can be represented by a base load situation. Consequently, for each realization and each year, six situations are calculated and weighted according to their probability of occurrence in order to get representative results of one year.

\begin{tabular}{|c|c|c|c|c|}
\hline & $\begin{array}{c}\text { low } \\
\text { wind }\end{array}$ & $\begin{array}{c}\text { medium } \\
\text { wind }\end{array}$ & $\begin{array}{c}\text { high } \\
\text { wind }\end{array}$ & \\
\hline peak load & $15 \%$ & $9 \%$ & $6 \%$ & $30 \%$ \\
\hline base load & $35 \%$ & $21 \%$ & $14 \%$ & $70 \%$ \\
\hline & $50 \%$ & $30 \%$ & $20 \%$ & $100 \%$ \\
\hline$\rightarrow$ feed-in & $6 \%$ & $19 \%$ & $46 \%$ & \\
\hline
\end{tabular}

Table IV. Weighting of the Wind feed-in Scenarios 


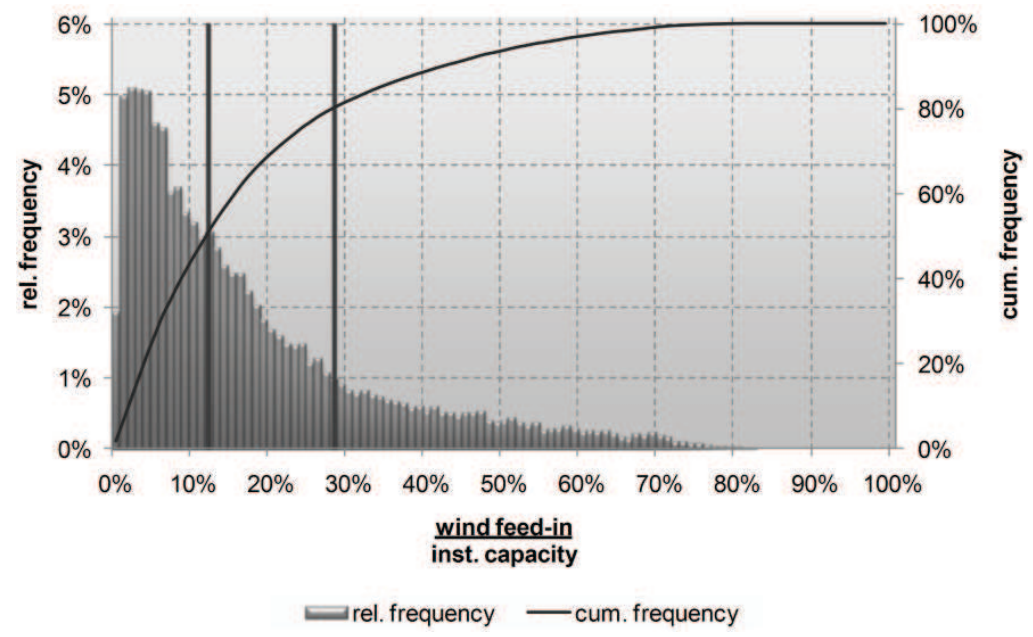

Fig. 6. Weighting of the calculations based on the frequency distribution of the wind feed-in

\section{Modeling wind capacity development}

The future development of wind capacity installations in Germany is possibly the single most important uncertain factor affecting investment decisions in transmission infrastructure. At the end of year 2009, a total of 21164 wind turbines with a cumulated rated power of $25.7 \mathrm{GW}$ were installed in Germany (Ender, 2010). Although onshore wind development already shows some symptoms of stagnation, the focus of further wind capacity additions is now on offshore wind farm installations in the North Sea and the Baltic Sea. Specialized agencies predict that installed wind power capacity could reach to about 65 GW in Germany by 2030 (DEWI, 2008).

The massive addition of wind power registered in Germany in the last decade and the foreseen huge offshore wind capacity integration to the existing networks make necessary major reinforcements of the transmission network. However, actual offshore wind development depends on a number of complex factors (technology advancements, cost development, regulatory framework, etc.) that make long-term forecasts highly uncertain. Given the high irreversibility and costs involved in major network upgrades, transmission expansion strategies that retain flexibility in order to adapt to unexpected or unlikely wind scenarios are particularly attractive. In order to properly assess the various investment alternatives, a wind capacity model that account for the ongoing uncertainties is required.

This section presents a novel stochastic model for simulating possible paths of the aggregate wind capacity development in Germany up to year 2030. The model specifically takes into consideration the different stages of maturity and development of onshore and offshore wind technology. Whereas onshore wind capacity growth is slowing down since peaked in 2002 and some constraints to further development are already evident (e.g. permits, land use, network restrictions, etc.), offshore wind development in Germany is in the very early stage and some rapid adoption rate it is expected for the coming years.

In order to model the penetration rates of wind energy technology, a stochastic logistic diffusion model is proposed for both, the onshore and the offshore capacity development processes. Besides population dynamics modeling, logistic curves have been widely used 
for modeling adoption rates and market penetration of many energy technologies (Lund, 2006, Lund, 2008; Usha Rao \& Kishore, 2010). Recently, S-shaped logistic growth have been extensively applied for modeling wind development trends in India and China (Carolin Mabel \& Fernandez, 2008; Changliang \& Zhanfeng, 2009; Pillai \& Banerjee , 2009; Usha Rao \& Kishore, 2009).

The logistic diffusion (Verhulst-Pearl) process is mathematically represented by the following first-order non-linear ordinary differential equation:

$$
\frac{d P(t)}{d t}=\beta P\left(1-\frac{P}{K}\right) \text { whose solution is given by } P(t)=\frac{K P_{0} e^{\beta t}}{K+P_{0}\left(e^{\beta t}-1\right)}
$$

where $P(t)$ is the wind power capacity installed at time $t, P_{0}$ is the capacity already installed at initial time $t_{0}, \beta$ is the mean adoption rate and $K$ the saturation level or maximum carrying capacity that the system can support.

Most of these mentioned logistic models assume a maximum capacity $K$ given by the wind potential of the relevant geographic region. While wind conditions play an important role, this maximum capacity should actually be regarded as an extreme upper bound to the wind development. In fact, in most circumstances, the maximum achievable capacity is significantly lower than this level and it is instead determined by other factors, such as site permits, regulatory framework, subsidizing mechanisms and grid and operational constraints, etc. The saturation level depends on the context and it might not be well correlated to the geographical wind potential. Unlike models establishing an exogenous maximum capacity, we use a rather different approach to establish the saturation level $K$. For onshore wind capacity, we estimate the adoption rate and the saturation level from the observed wind development itself and for offshore wind capacity installations from available forecast data.

By expressing the logistic differential equation in terms of its finite difference approximation we obtain:

$$
\frac{\Delta P_{t}}{\Delta t}=\frac{P_{t+1}-P_{t}}{\Delta t}=\beta P_{t}\left(1-\frac{P_{t}}{K}\right) ; \text { solving for } P_{t+1} \text { we get } P_{t+1}=\beta P_{t}\left(1-\frac{P_{t}}{K}\right) \Delta t+P_{t}
$$

what forms the basis for implementing a numerical simulation model of the wind capacity development. We can estimate parameters $\beta$ and $K$ by expressing the observed fractional growth rate $\Delta P_{t} /\left(P_{t} \Delta t\right)$ in terms of the linear regression model where $\varepsilon_{t}$ is a zero-mean independent normally distributed error residual term with finite variance $\sigma^{2}$ :

$$
\frac{\Delta P_{t}}{P_{t}} \frac{1}{\Delta t}=\hat{\beta}-\hat{\lambda} P_{t}+\varepsilon_{t} \quad \varepsilon_{t} \sim N(0, \sigma) \text { where } \hat{\lambda}=\frac{\hat{\beta}}{\hat{K}}
$$

Fig. 7 illustrates the observations, the regressed line and the estimated parameters as well as the obtained regression residuum. Analysis of residuals shown in Fig. 8 conforms to the hypothesis of Gaussianity and independence required by the linear regression model.

Based on the linear regression model stated above, we can numerically generate sample development paths for the installed wind capacity by adding the stochastic error term $\varepsilon_{t} \sim N(0, \sigma)$ to the logistic difference equation. Fig. 9 depicts the observed and expected 

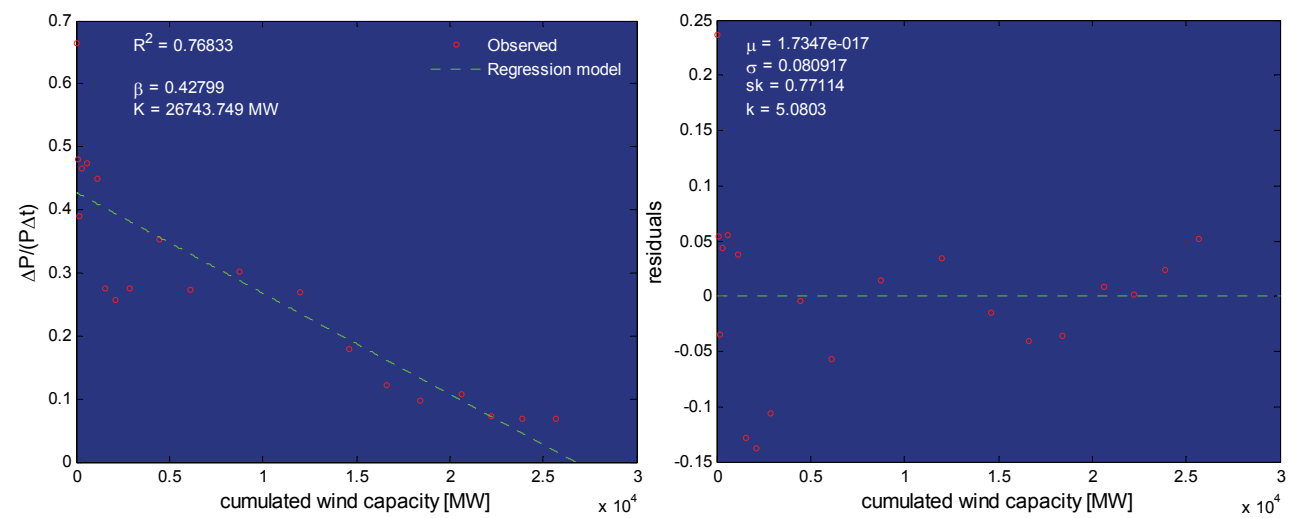

Fig. 7. Estimated logistic model of wind power capacity in Germany and resulting regression residuals
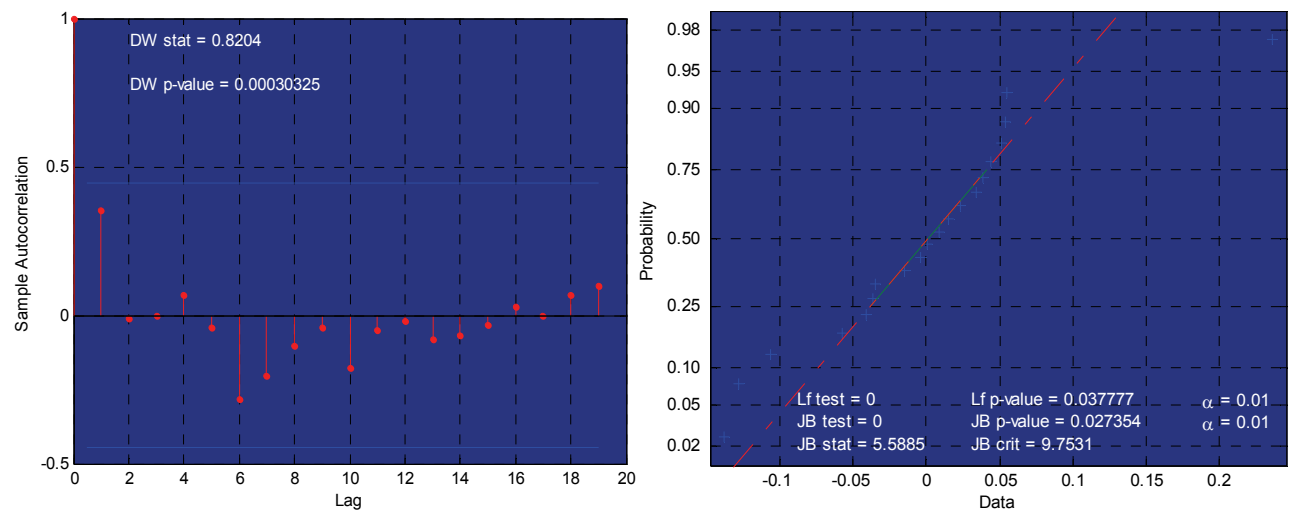

Fig. 8. Normal probability plot, Jarque-Bera/Lilliefors test statistics and autocorrelation of residuals

onshore wind capacity development in the future along with the $95 \%$ confidence bounds. It should be noticed that for the current conditions, the logistic growth model suggests that onshore wind development in Germany is already near saturation. Furthermore, uncertainty on future evolution of onshore capacity is not a severe issue as the logistic process is almost complete.

The diffusion process of the offshore wind technology in Germany is right in its beginning and therefore the ongoing uncertainties on the future development are huge. The substantial involved uncertainties are evident from the large spread shown by wind capacity forecasts for Germany collected from a number of agencies and institutions (Nitsch, 2005), as illustrated in Fig. 10 (left). The logistic regression model is applied to the prediction ensemble data in order to estimate the adoption rate and the capacity saturation level implied by forecasts (see Fig. 10 right). As it can be noticed from the scatter plot and residuals, predictions on the future offshore wind capacity development are subjected to high uncertainties. 


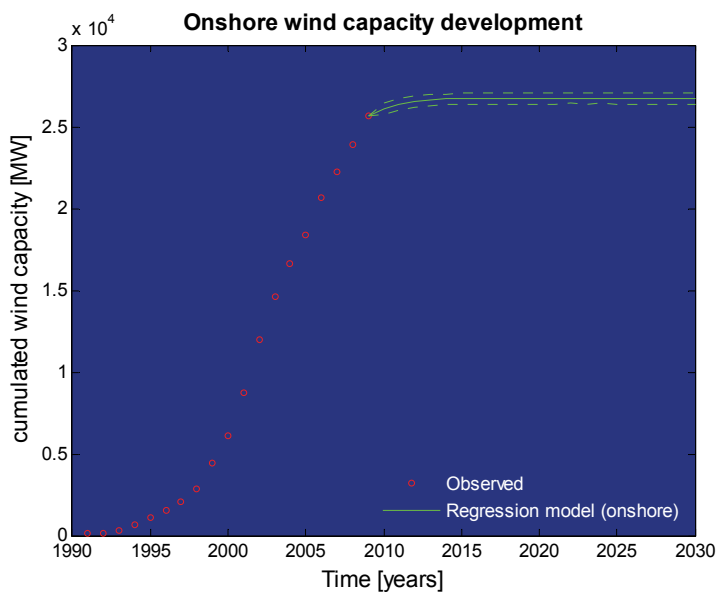

Fig. 9. Uncertainty on the future development of onshore wind power
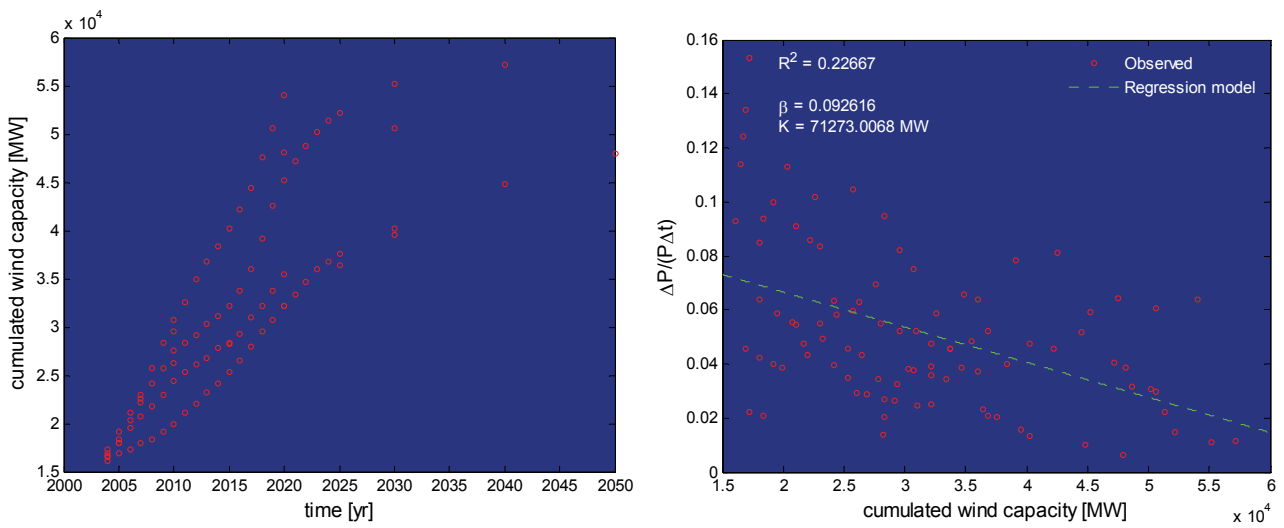

Fig. 10. Wind capacity forecast ensemble and estimated logistic model to forecast data

As there are still no available observations, the describe approach unfortunately does not apply to the stochastic simulation of the possible scenarios of offshore wind power capacity. However, the estimated parameters $\hat{\beta}$ and $\hat{\lambda}$ in the offshore logistic model are actually independent random variables normally distributed, for which confidence intervals can be computed from the Student's T-distribution. This confidence bounds allows estimating the standard deviation of each estimated parameter, $\hat{\sigma}_{\beta}$ and $\hat{\sigma}_{\lambda}$ respectively. These confidence intervals represent the uncertainty implied by the currently available forecasts. We can generate different logistic development paths for the offshore wind capacity by properly sampling model parameters values for their corresponding normal distributions, $N\left(\hat{\beta}, \sigma_{\beta}\right)$ and $N\left(\hat{\lambda}, \hat{\sigma}_{\lambda}\right)$.

After computing a large number of sample paths, Fig. 11 shows the resulting expected development of the total (onshore + offshore) wind power capacity in Germany up to year 2030 along with the rather wide 95\% confidence bound, which in turns reflect the substantial current uncertainties on offshore wind installations. It is worth to mention, that 
the logistic offshore model suggest a much slow adoption of the offshore wind technology as conventionally reported.

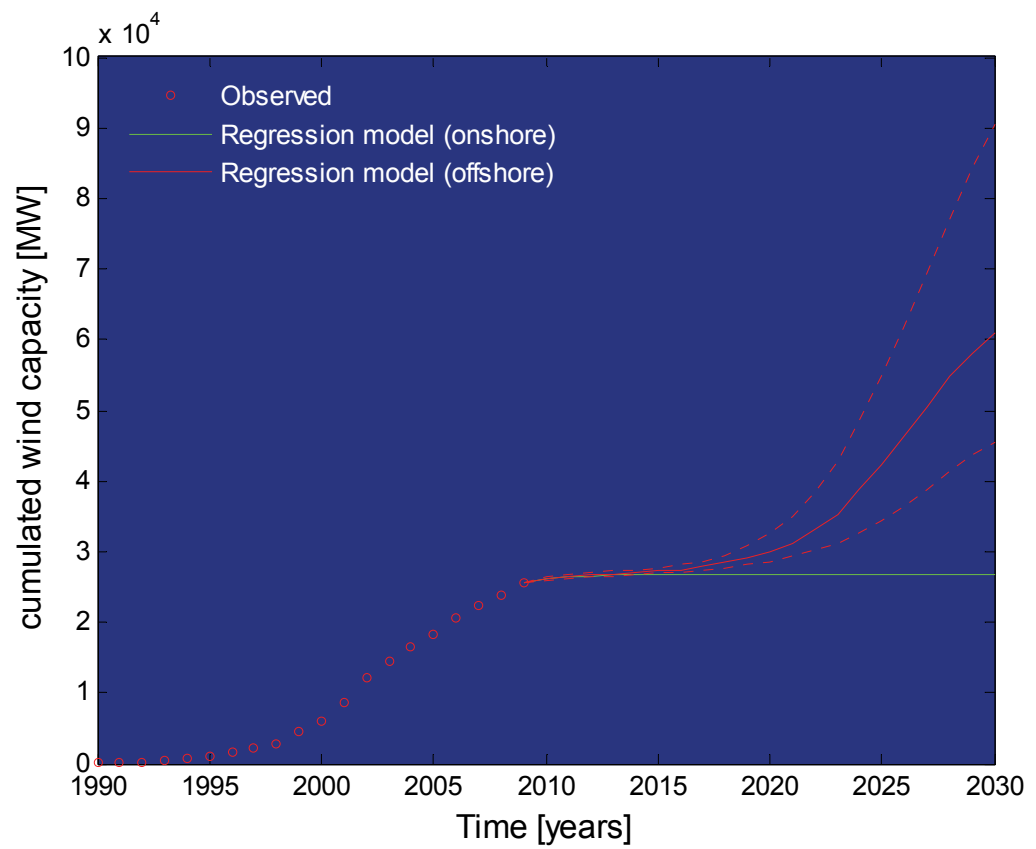

Fig. 11. Stochastic logistic simulations of the total wind power capacity development in Germany

\subsection{Valuing flexible investment portfolios in the transmission system}

The cost savings (CS) are estimated for each realization on the investment horizon by means of the Monte Carlo simulation. A stochastic cash flow for the investment projects can be numerically simulated. The resulting cash flow of each Monte Carlo realization is composed of the annual cost saving $C S_{i, \omega}^{s}$, investments costs $\left(I_{s, t_{n}}\right)$ and operation cost $\left(O C_{s, t_{n}}\right)$.

Later on, this cash flow is discounted by the hurdle rate of the investment $(\rho)$ in order to obtain the present value of the Incremental Social Welfare (ISW), which can be stated as following:

$$
\begin{gathered}
P V(I S W)_{s, \omega, t_{n}}=\sum_{i=t_{n}}^{M}\left(\frac{C S_{i, \omega}^{s}}{(1+\rho)^{i}}\right) ; \\
N P V(I S W)_{s, \omega, t_{n}}=\sum_{i=t_{n}}^{M}\left(\frac{C S_{i, \omega}^{s}-I_{s, i}-O C_{s, i}}{(1+\rho)^{i}}\right) ; \\
E\left[N P V(I S W)_{s, \omega, t_{n}}\right]=\sum_{\omega=1}^{\Omega} \frac{1}{\Omega}\left(N P V(I S W)_{s, \omega, t_{n}}\right)
\end{gathered}
$$


where $C S_{i, \omega}^{S}$ and $I_{s, i}$ are the generation cost savings and the investment cost respectively in the $\omega$ realization, $P V\left(I S W_{s, k}^{j}\right)$ and $N P V\left(I S W_{s, k}^{j}\right)$ are the Present Value (PV) and Net Present Value (NPV) of the ISW by executing the investment strategy $s$ in the year $t_{n}$ and by $M$ the investment horizon, finally, $E\left[N P V(I S W)_{s, \omega, t_{n}}\right]$ is its expected value for $\Omega$ Monte Carlo realizations. In each case, the subscripts correspond to the $h$-th hour, $i$-th year, $\omega$-th realization of the Monte Carlo power system simulation.

Within this chapter, the following have been considered as investment alternatives: firstly, a FACTS device and afterwards, a transmission line (TL). Therefore, the available investment options either invest in the FACTS first, in the line first or both in the FACTS and the line. The strategic flexibility of postponing both investments as well as abandoning or relocating the FACTS device are compounded options. Hence, these available options are valued by means of the LSM method, by applying the following Bellman's equations (Blanco, 2010):

1. Option to invest in the FACTS first:

$$
F_{F}\left(t_{n}, X_{t_{n}}\right)=\max \left\{\begin{array}{l}
\Pi_{F}\left(t_{n}, X_{t_{n}}\right)+\max \left(F_{R}\left(t_{n+1}, X_{t_{n+1}}\right) ; F_{A}\left(t_{n+1}, X_{t_{n+1}}\right) ; F_{T L}^{F}\left(t_{n+1}, X_{t_{n+1}}\right)\right) \cdot d f ; \\
\cdots \mathbb{E}_{t_{n}}^{*}\left[F_{F}\left(t_{n+1}, X_{t_{n+1}}\right)\right] \cdot d f
\end{array}\right\}
$$

2. Option to invest in the line first:

$$
F_{T L}\left(t_{n}, X_{t_{n}}\right)=\max \left\{\Pi_{T L}\left(t_{n}, X_{t_{n}}\right)+F_{F}^{T L}\left(t_{n+1}, X_{t_{n+1}}\right) \cdot d f ; \mathbb{E}_{t_{n}}^{*}\left[F_{T L}\left(t_{n+1}, X_{t_{n+1}}\right)\right] \cdot d f\right\}
$$

3. Option to invest both in the FACTS and the line:

$$
F_{T L \& F}\left(t_{n}, X_{t_{n}}\right)=\max \left\{\begin{array}{l}
\Pi_{T L \& F}\left(t_{n}, X_{t_{n}}\right)+\max \left(F_{R}^{T L \& F}\left(t_{n+1}, X_{t_{n+1}}\right) ; F_{A}^{T L \& F}\left(t_{n+1}, X_{t_{n+1}}\right)\right) \cdot d f \\
\cdots \mathbb{E}_{t_{n}}^{*}\left[F_{T L \& F}\left(t_{n+1}, X_{t_{n+1}}\right)\right] \cdot d f
\end{array}\right\}
$$

where $F_{m}^{n}\left(t_{n}, X_{t_{n}}\right)$ is the option value and $\Pi_{m}^{n}\left(t_{n}, X_{t_{n}}\right)$ the profit value, both for the option $m$ (F: FACTS, TL: transmission line, $R$ : FACTS relocation, $A$ : FACTS abandon) in the state $n$ ( $F$ : FACTS investment done, $T L$ : line investment done, $A b$ : FACTS abandon done. Expanding the equation (26):

$$
\begin{gathered}
F_{R}\left(t_{n}, X_{t_{n}}\right)=\max \left\{\begin{array}{l}
\Pi_{R}\left(t_{n}, X_{t_{n}}\right)+\max \left(F_{T L}^{R}\left(t_{n}, X_{t_{n}}\right) ; F_{A}\left(t_{n+1}, X_{t_{n+1}}\right) \cdot d f\right) ; \cdots \\
\mathbb{E}_{t_{n}}^{*}\left[F_{R}\left(t_{n+1}, X_{t_{n+1}}\right)\right] \cdot d f
\end{array}\right\} \\
F_{A}\left(t_{n}, X_{t_{n}}\right)=\max \left\{\Pi_{A}\left(t_{n}, X_{t_{n}}\right)+F_{T L}^{A}\left(t_{n}, X_{t_{n}}\right) ; \mathbb{E}_{t_{n}}^{*}\left[F_{A}\left(t_{n+1}, X_{t_{n+1}}\right)\right] \cdot d f\right\} \\
F_{T L}^{F}\left(t_{n}, X_{t_{n}}\right)=\max \left\{\begin{array}{l}
\Pi_{T L}^{F}\left(t_{n}, X_{t_{n}}\right)+\max \left(F_{R}^{T L \& F}\left(t_{n+1}, X_{t_{n+1}}\right) ; F_{A b}^{T L \& F}\left(t_{n+1}, X_{t_{n+1}}\right)\right) \cdot d f ; \\
\cdots \mathbb{E}_{t_{n}}^{*}\left[F_{T L}^{F}\left(t_{n+1}, X_{t_{n+1}}\right)\right] \cdot d f
\end{array}\right\}
\end{gathered}
$$


Likewise, expanding the equations (29) and (30):

$$
\begin{gathered}
F_{F}^{T L}\left(t_{n}, X_{t_{n}}\right)=\max \left\{\begin{array}{l}
\Pi_{F}^{T L}\left(t_{n}, X_{t_{n}}\right)+\max \left(F_{R}^{T L \& F}\left(t_{n+1}, X_{t_{n+1}}\right) ; F_{A b}^{T L \& F}\left(t_{n+1}, X_{t_{n+1}}\right)\right) \cdot d f ; \\
\cdots \mathbb{E}_{t_{n}}^{*}\left[F_{F}^{T L}\left(t_{n}, X_{t_{n+1}}\right)\right] \cdot d f
\end{array}\right\} \\
F_{R}^{T L \& F}\left(t_{n}, X_{t_{n}}\right)=\max \left\{\Pi_{R}^{T L \& F}\left(t_{n}, X_{t_{n}}\right)+F_{A b}^{T L \& F, R}\left(t_{n+1}, X_{t_{n+1}}\right) \cdot d f ; \mathbb{E}_{t_{n}}^{*}\left[F_{R}^{T L \& F}\left(t_{n+1}, X_{t_{n+1}}\right)\right] \cdot d f\right\} \\
F_{A}^{T L \& F}\left(t_{n}, X_{t_{n+1}}\right)=\max \left\{\Pi_{A}^{T L \& F}\left(t_{n}, X_{t_{n}}\right) ; \mathbb{E}_{t_{n}}^{*}\left[F_{A}^{T L \& F}\left(t_{n+1}, X_{t_{n+1}}\right)\right] \cdot d f\right\}
\end{gathered}
$$

For the investment option exercising:

$$
\Pi_{m}^{n}\left(t_{n}, X_{t_{n}}(\omega)\right)=P V(I S W)_{s, \omega, t_{n}}-I_{s, t_{n}, \omega}
$$

where $I_{s, t_{n}, \omega}$ is the investment cost of the $s$-th investment strategy at the $t_{n}$-th year. On the other hand, in the relocation and abandon cases:

$$
\begin{aligned}
& \Pi_{R}^{n}\left(t_{n}, X_{t_{n}}(\omega)\right)=P V\left(I S W_{R, t_{n}, \omega}\right)-C R_{t_{n}, \omega} \\
& \Pi_{A}^{n}\left(t_{n}, X_{t_{n}}(\omega)\right)=S V_{t_{n}, \omega}-P V(I S W)_{s, \omega, t_{n}}
\end{aligned}
$$

where $C R_{t_{n}, \omega}$ is the relocation cost and $S V_{t_{n}, \omega}$ is the scrap value of the FACTS devices by the $t_{n}$-th year.

The resulting cash flow is estimated according to each available investment strategy. It is relevant to remark that all possible investment strategies and their intrinsic real options are evaluated exhaustively, so that all possible combinations among the available flexibility options are assessed.

The option values for each strategy are calculated by applying this procedure. Hence, the optimal investment strategy is the one with the highest value. It is important to note that the optimal decision policy obtained by the LSM approach is not a deterministic one. In fact, there is an optimal policy for each simulated path. Consequently, a probability density function of option values can be determined.

The precision of the estimation value of the options might be improved by increasing the number of time steps $N$ and the number of simulated path $\Omega$. In this sense, the Monte Carlo stop criterion applied is the control of the relative error (Fishman, 2005). Setting $\delta=10 \%$ entails demanding a confidence level in the attributes assessment of $95 \%$.

$$
\varepsilon_{S}\left(F_{n}^{m}(0), \sigma_{F_{n}^{m}(0)}\right)=\frac{\phi^{-1}\left(1-\frac{\delta}{2}\right) \cdot \sigma_{F_{n}^{m}(0)}}{F_{n}^{m}(0) \cdot \sqrt{\Omega}}
$$


where $\phi^{-1}$ is the inverse of the Standard Normal Distribution (SND), $(1-\delta / 2)$ the confidence level specified, $\phi^{-1}(1-\delta / 2)$ the critical value of a SND with mean 0 and standard deviation 1 and $\sigma_{F_{n}^{m}(0)}$ the volatility of the expected option value. In this chapter it is assumed as maximum relative error $1 \%$.

\section{Study cases}

The influence of two network upgrades on the out-of-merit cost is evaluated based on the approach presented in the previous section. These reinforcements projects are the development of a new 380-kV-double circuit and/or the installation of a FACTS controller. Both upgrades represent measures to strengthen the German network. Hence, a static and inflexible expansion project, which is currently under study, is compared to flexible investment in order to shed some light on the impact of the strategic flexibility on the optimal decision making process. The reinforcement alternatives have the following characteristics:

- Reinforcement 1: Development of a new 380-kV- double circuit on a length of $167 \mathrm{~km}$ between nodes 20 and 25, leading to investment costs of about $117 \mathrm{M} €$.

- Reinforcement 2: Installation of a TCSC devices of 286/-80 MVar between nodes 21 and 25 , with the option to further relocate it between the nodes 20 and 25, leading to investment costs of about 47,63 M€ (Schaffner, 2004). Moreover, the relocation cost of the FACTS controller and its residual value are taken equal to $40 \%$ and $20 \%$ of the total FACTS cost respectively.

Thus, as starting point, there are three mutually exclusive alternatives (options) to be assessed, namely:

- Investing in the FACTS device first $\left(\mathrm{S}_{1}\right)$,

- investing in the transmission line first $\left(\mathrm{S}_{2}\right)$ or,

- investing in the FACTS and line jointly $\left(\mathrm{S}_{3}\right)$.

Maturity is set for all investments options equal to three years and 15 years as the investment horizon. Lead construction time is assumed to be one year and discount rate is considered to $8 \%$ per year, for all considered investment alternatives.

The network and data described in the previous sections is applied to compute 1000 sample realizations for ensuring the maximum relative error established before. Hence, several OPF calculations are performed for each scenario (base and investment). By this means, the stochastic annual generation cost savings are estimated.

The results of the investment evaluations are depicted in Table V. The traditional NPV appraisal suggests $S_{3}$ as the optimal investment choice. Conversely, the real option valuation determines $S_{1}$ as the optimal decision by taking into account the strategic flexibility provided on each strategy. Since the option value can be calculated according to (9), the economic value of the flexibility of each investment strategy is given by subtracting the expected NPV of the expected option value.

It should be highlighted that the investment alternative with the higher flexibility value is $S_{1}$, investing in FACTS first. This can be explained by noting that the flexibility of FACTS remains after the investment option has been exercising allowing a better adaption to possible adverse scenarios in the long-term. 


\begin{tabular}{|c|c|c|c|}
\hline Strategy & $\mathbb{E}[$ Option Value $](M €)$ & $\mathbb{E}[$ NPV value $](M €)$ & Flexibility (M€) \\
\hline$S_{1}$ & $140.14\left(1^{\text {st }}\right)$ & $48.26\left(3^{\text {rd }}\right)$ & $91.882\left(1^{\text {st }}\right)$ \\
\hline$S_{2}$ & $91.03\left(2^{\text {nd }}\right)$ & $57.347\left(2^{\text {nd }}\right)$ & $33.782\left(2^{\text {nd }}\right)$ \\
\hline$S_{3}$ & $90.447\left(3^{\text {rd }}\right)$ & $90.441\left(1^{\text {nd }}\right)$ & $0.006\left(3^{\text {rd }}\right)$ \\
\hline
\end{tabular}

Table V. Ranking of expansion strategies by applying the proposed evaluation approach and the traditional appraisal

Table VI portrays the feasible structure of the RO portfolios and its respective value. Thus, for instance, the structure TL-F-R-A implies that the option to invest in the TL, FACTS, relocation and abandon are available. It is important to notice that in all the RO portfolios, the deferral option is considered available.

As can be also seen, the $S_{1}$ value decreases when are unavailable the abandon and relocation options. This means that these options are worth and its valuation is relevant. Thus, in the situation where the relocation option is unavailable, the optimal decision is to invest in the TL first.

In a portfolio which includes FACTS, an important option is the option to defer the new TL. This can be observed by comparing the option values with (TL-F-R-A) and without (F-R-A) in their set of options. By comparing this value with the flexibility value of $S_{1}$ is easy to note that the largest flexibility of the strategic to invest in FACTS first is the TL deferral option.

On the other hand, the value of the deferral option of the TL can be obtained from the option by subtracting the $S_{2}$ (TL) portfolio value minus the static $\mathrm{NPV}\left(\mathrm{S}_{2}\right)$ of Table $\mathrm{V}$. In this particular study case, this value is low. Therefore, it possible to conclude that if the FACTS device is not regarded as an investment strategy the execution of the TL is probably going to be executed.

\begin{tabular}{|c|c|c|c|c|c|c|c|c|c|}
\hline \multirow{2}{*}{ Strategy } & \multicolumn{8}{|c|}{ Available Options Value $[\mathrm{M} €]$} \\
\cline { 2 - 11 } & TL-F-R-A & TL-F-R & TL-F-A & TL-F & F-R-A & F-R & F-A & F & TL \\
\hline $\mathrm{S}_{1}$ & 140.14 & 96.18 & 88.807 & 88.44 & 70.52 & 70.51 & 48.27 & 48.26 & \\
\hline $\mathrm{S}_{2}$ & 91.03 & 90.742 & 91.02 & 90.74 & & & & & 58.6 \\
\hline $\mathrm{S}_{3}$ & 90.45 & 89.04 & 90.45 & 89.04 & & & & & \\
\hline
\end{tabular}

Table VI. Option Value and the composition of the option portfolio.

The probability density function (PDF) of the option value is illustrated in Fig. 12. By mean of this figure, it can be observed that both $S_{2}$ and $S_{3}$ have a relevant downside risk in comparison with $S_{1}$. This risk acquires more relevance due to the facts that the TL expansions are irreversible investments. For that reason, the inclusion of flexibility in the TI problem is needed. In this sense, FACTS devices allow making expansions, retaining flexibility for properly managing uncertainties of the TI problem.

\section{Conclusion}

In this chapter, the application of a new approach has been developed for assessing flexible options embedded in investments projects. The option values have their roots in the fact that they put a floor against possible project losses. It has been shown that static NPV methods may be inappropriate for assessing flexible investments, since the existence of uncertainties 


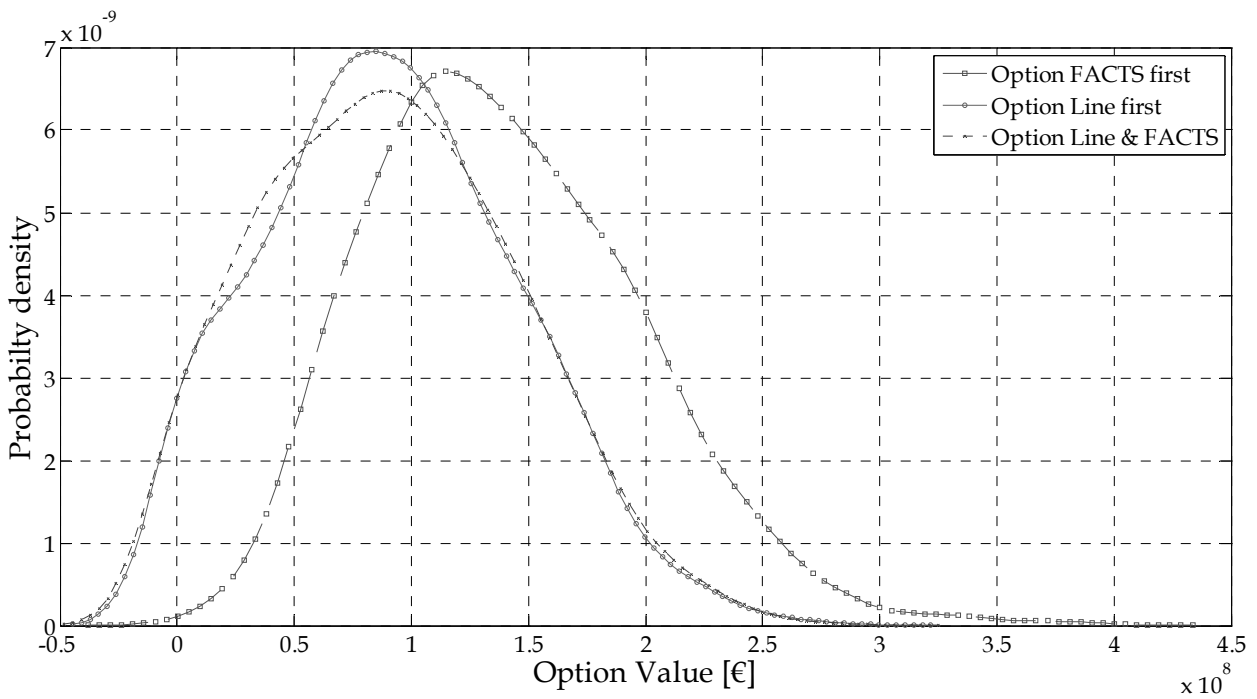

Fig. 12. Probability density function (PDF) of the analyzed strategies.

significantly increment the value of the strategic flexibility embedded in the decisionmaking process. In this sense, a RO framework has been developed, using the novel LSM simulation approach for solving the stochastic optimization problem.

The proposed appraisal framework was focused on the economic quantification of the main flexibility options in transmission investments projects. Particularly, flexible options of FACTS devices, i.e. postponement of large transmission project execution, relocation and abandonment of the controller was analyzed. The main uncertain variables and risks to which transmission projects are exposed, have been modelled. Long-term uncertainties have properly been handled by incorporating flexible expansion projects aiming at improving investment risk profiles. Particularly, this chapter included a novel modeling approach based on logistic diffusion process to the generation of future wind capacity scenarios. Finally, the flexibility value has been quantified for the postponement, relocation or abandonment of an investment project.

In a study case, it has been shown that more flexible investment strategies can be obtained and the adaptability to uncertain future scenarios is considerably improved by suitably combining FACTS controllers and conventional investments in transmission lines over the considered time horizon. In addition, it has been illustrated how the optimal decision could be misleaded under the traditional NPV investment rule. Hence, by applying the proposed $\mathrm{RO}$ valuation approach an important but yet uninvestigated feature of FACTS devices has been remarked: inducing investment execution in stages and postponing large and irreversible transmission line projects.

\section{References}

Amram, M., \& Kulatilaka N. (1998). Real Options: Managing Strategic Investment in an Uncertain World. Oxford University Press, ISBN-10: 0875848451, USA. 
Black, F., and M. S Scholes. 1973. The Pricing of Options and Corporate Liabilities. Journal of Political Economy 81, no. 3. Journal of Political Economy: 637-54.

Blanco, G., Waniek D., Olsina F., Garcés F., \& Rehtanz, C. (2010a). Flexible Investment Decisions in the European Interconnected Transmission System, Electric Power System Research, EPSR-D-10-00390, doi: 10.1016/j.epsr.2010.12.001 (accepted for publication).

Blanco, G. (2010b). Evaluación de portafolios de inversiones flexibles en el sistema de transmisión incluyendo dispositivos FACTS. Ph.D. Dissertation. Editorial Fundación de la Universidad Nacional de San Juan, ISBN: 978-987-05-8411-7Argentina.

Blumsack, S., Apt, J. \& Lave, L. B. (2006). Lessons from the Failure of U.S. Electricity Restructuring. The Electricity Journal, 19, no. 2 (March): 15-32.

Brealey, R. A., Myers, S. C. \&. Allen, F. (1996). Principles of Corporate Finance. 9th ed. McGraw-Hill Companies, ISBN-10: 0071266755, USA.

Brosch, R. (2001). Portfolio-aspects in real options management. Department of Finance, Goethe University Frankfurt am Main, February. RePEc.

Carolin Mabel, M. \& Fernandez, E. (2008). Growth and future trends of wind energy in India, Renewable and Sustainable Energy Reviews, Vol. 12 (6), pp. 1745-1757.

Changliang, X. \& Zhanfeng, S. (2009) . Wind energy in China: Current scenario and future perspectives, Renewable and Sustainable Energy Reviews, Vol. 13 (8), pp. 1966-1974.

Copeland, T. \& Antikarov V. (2003). Real Options, Revised Edition: A Practitioner's Guide. 1st ed. Texere, ISBN: 1587991705, USA.

Cortazar, G., Gravet, M., \& Urzua J. (2008). The valuation of multidimensional American real options using the LSM simulation method. Computers \& Operations Research 35, no. 1 (January): 113-129.

Cox, J. C., Ross, S. \& Rubinstein, M. (1979). Option pricing: A simplified approach. Journal of Financial Economics 7, no. 3. Journal of Financial Economics: 229-263.

Damodaran, A. (2002). Investment Valuation. 2nd Edition University with Investment Set. 2nd ed. Wiley, ISBN-13: 978-0471280811, USA.

DEWI, Deutsches Windenergie-Institut (2008). WindEnergy Study 2008, Husum WindEnergy, 9-13 September 2008, Husum, Germany.

Dixit, A. K., \& Pindyck, R.(1994). Investment under Uncertainty. Princeton University Press, ISBN-10: 0691034109, USA.

Ender, C. (2010). Wind Energy Use in Germany - Status 31.12.2009, DEWI Magazine, Vol. 36, pp. 28-41.

ENTSOE. (2009). Online Database [Online]. Available: www.entsoe.eu

Fishman, G. (1995). Monte Carlo: Concepts, Algorithms, and Applications, New York: Springer, ISBN 038794527X, USA.

Gamba, A. (2003). Real Options Valuation: A Monte Carlo Approach. SSRN eLibrary (December).

Garver, L.L. (1970). Transmission Network Estimation Using Linear Programming. Power Apparatus and Systems, IEEE Transactions on PAS-89, no. 7: 1688-1697.

IER. (2007). Energy System Development in Germany, Europe and Woldwide.

Latorre, G., Cruz, R.D.,.Areiza, J.M, \& Villegas A. (2003). Classification of publications and models on transmission expansion planning. Power Systems, IEEE Transactions on 18, no. 2: 938-946. 
Longstaff, F. A. \& Schwartz E.. 2001. Valuing American Options by Simulation: A Simple Least-Squares Approach. Review of Financial Studies 14, no. 1. Review of Financial Studies: 113-47.

Lund, P. (2006). Market penetration rates of new energy technologies, Energy Policy, Vol. 34 (17), pp. 3317-3326.

Lund, P. (2010). Exploring past energy changes and their implications for the pace of penetration of new energy technologies, Energy, Vol. 35 (2), pp. 647-656.

Myers, S. (1977). Determinants of corporate borrowing. Journal of Financial Economics 5, no. 2 (November): 147-175.

Nitsch, J., Staiß, F., Wenzel, B. \& Fischedick, M. (2005). Ausbau Erneuerbarer Energien im Stromsektor bis zum Jahr 2020, Bundesministeriums für Umwelt, Naturschutz und Reaktorforschung, Germany.

Olafsson, S. (2003). Making Decisions Under Uncertainty - Implications for High Technology Investments. BT Technology Journal 21, no. 2: 170-183.

Olsina, F., Garcés F. \& Haubrich H-J. (2006). Modeling long-term dynamics of electricity markets. Energy Policy 34, no. 12 (August): 1411-1433.

Olsina, F., Röscher, M, Larisson C. \& F. Garcés. (2007). Short-term optimal wind power generation capacity in liberalized electricity markets. Energy Policy 35, no. 2 (February): 1257-1273.

Pillai, I. \& Banerjee, R. (2009). Renewable energy in India: Status and potential, Energy, Vol. 34 (8), pp. 970-980.

Rodrigues, A. \& Rocha, M. (2006). The Valuation of Real Options with the Least Squares Monte Carlo Simulation Method. Working Paper. SSRN eLibrary (February).

Romero, R. \& Monticelli, A. (1994). A hierarchical decomposition approach for transmission network expansion planning. Power Systems, IEEE Transactions on 9, no. 1: 373-380.

Seifu, A., Salon, S. \& List, G. (1989). Optimization of transmission line planning including security constraints. Power Systems, IEEE Transactions on 4, no. 4: 1507-1513.

Trigeorgis, L. (1996). Real Options: Managerial Flexibility and Strategy in Resource Allocation. The MIT Press, ISBN-13: 978-0262201025, USA.

Usha Rao \& K., Kishore, V. (2010). A review of technology diffusion models with special reference to renewable energy technologies, Renewable and Sustainable Energy Reviews, Vol. 14 (3), pp. 1070-1078.

Usha Rao, K. \& Kishore, V. (2009). Wind power technology diffusion analysis in selected states of India, Renewable Energy, Vol. 34 (4), pp. 983-988.

Vásquez, P. \& Olsina, F. (2007). Valuing Flexibility of DG Investments in Transmission Expansion Planning, Proceeding of Power Tech, 2007 IEEE Lausanne, 695-700, July 2007, IEEE-PES, Lausanne.

Vásquez, P. 2009. Flexibility-based decision-making for facing the current transmission expansion planning problem. PhD Thesis, Instituto de Energía Eléctrica, UNSJ San Juan, ISBN: 978-987-05-6401-0.

Wang, X., Song, Y.H., Lu, Q. \& Sun Y. (2002). Optimal allocation of transmission rights in systems with FACTS devices. Generation, Transmission and Distribution, IEE Proceedings- 149, no. 3: 359-366.

Waniek, D., Rehtanz C. \& Handschin E. (2009). Analysis of market coupling based on a combined network and market model. Proceeding of PowerTech, 2009 IEEE Bucharest, 1-6, July 2009, IEEE-PES, Bucharest. 
Weber, C. (2004). Uncertainty in the Electric Power Industry: Methods and Models for Decision Support. 1st ed. Springer, ISBN-10: 0387230475, Germany.

Yu, C., Leotard, J. \& Ilić M. (1999). Dynamic Transmission Provision in Competitive Electric Power Industry. Discrete Event Dynamic Systems: Theory and Applications, 9, Kluwer Academic Publishers, Boston, MA.

Zhang, X., C. Rehtanz, and B. Pal. 2006. Flexible AC Transmission Systems: Modelling and Control. 1st ed. Springer, ISBN-10: 3540306064, Germany. 


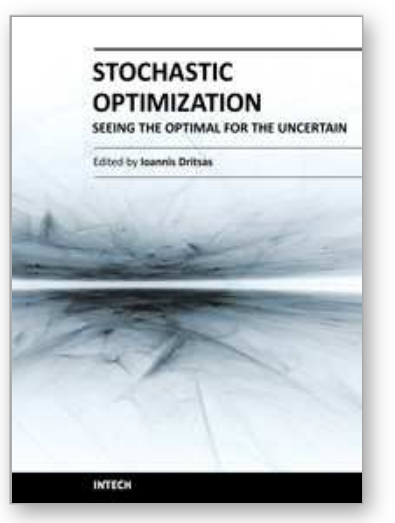

\author{
Stochastic Optimization - Seeing the Optimal for the Uncertain \\ Edited by Dr. loannis Dritsas
}

ISBN 978-953-307-829-8

Hard cover, 476 pages

Publisher InTech

Published online 28, February, 2011

Published in print edition February, 2011

Stochastic Optimization Algorithms have become essential tools in solving a wide range of difficult and critical optimization problems. Such methods are able to find the optimum solution of a problem with uncertain elements or to algorithmically incorporate uncertainty to solve a deterministic problem. They even succeed in â€œfighting uncertainty with uncertaintyâ€. This book discusses theoretical aspects of many such algorithms and covers their application in various scientific fields.

\title{
How to reference
}

In order to correctly reference this scholarly work, feel free to copy and paste the following:

Gerardo Blanco and Fernando Olsina (2011). Optimal Decision-Making under Uncertainty - Application to Power Transmission Investments, Stochastic Optimization - Seeing the Optimal for the Uncertain, Dr. loannis Dritsas (Ed.), ISBN: 978-953-307-829-8, InTech, Available from: http://www.intechopen.com/books/stochasticoptimization-seeing-the-optimal-for-the-uncertain/optimal-decision-making-under-uncertainty-application-topower-transmission-investments

\section{INTECH}

open science | open minds

\section{InTech Europe}

University Campus STeP Ri

Slavka Krautzeka 83/A

51000 Rijeka, Croatia

Phone: +385 (51) 770447

Fax: +385 (51) 686166

www.intechopen.com

\section{InTech China}

Unit 405, Office Block, Hotel Equatorial Shanghai

No.65, Yan An Road (West), Shanghai, 200040, China

中国上海市延安西路65号上海国际贵都大饭店办公楼 405 单元

Phone: +86-21-62489820

Fax: $+86-21-62489821$ 
(C) 2011 The Author(s). Licensee IntechOpen. This chapter is distributed under the terms of the Creative Commons Attribution-NonCommercialShareAlike-3.0 License, which permits use, distribution and reproduction for non-commercial purposes, provided the original is properly cited and derivative works building on this content are distributed under the same license. 